NBER WORKING PAPER SERIES

\title{
THE EVOLUTION OF INEQUALITY, HETEROGENEITY AND UNCERTAINTY IN LABOR EARNINGS IN THE U.S. ECONOMY
}

\author{
Flavio Cunha \\ James J. Heckman \\ Working Paper 13526 \\ http://www.nber.org/papers/w13526
NATIONAL BUREAU OF ECONOMIC RESEARCH
1050 Massachusetts Avenue
Cambridge, MA 02138
October 2007

\begin{abstract}
This research was supported by NIH R01-HD-043411 and NSF SES-0241858. Cunha is grateful to the Claudio Haddad Dissertation Fund at the University of Chicago and Rob Dugger for research support. This article builds on research reported in Cunha, Heckman and Navarro (2005). We are grateful to Ray Fair, Lars Hansen, Pat Kehoe, Robert Lucas, Salvador Navarro, Tom Sargent, Robert Shimer, Robert Townsend and Kenneth Wolpin for comments on various drafts. This version has benefited from comments received at the Money and Banking Workshop, University of Chicago, November 21,2006 . We have also benefited from comments received from participants at the Ely Lectures at Johns Hopkins University, April 2005, the 9th Econometric Society World Congress at University College London, August 2005, the Economic Dynamics Working Group at the University of Chicago, October 2005, the Empirical Dynamic General Equilibrium Conference at the Centre for Applied Microeconometrics, December 2005, the Macroeconomics of Imperfect Risk Sharing Conference at the University of California at Santa Barbara, May 2006, the 2006 Meetings of the Society for Economic Dynamics, July 2006, the Koopmans Memorial Lectures at Yale, September 2006, the Federal Reserve Bank of Minneapolis Applied Micro Workshop, October 2006, and Tom Sargent's Macro Reading Group at New York University, October 2006. The website for the supplementary material to this paper is http://jenni.uchicago.edu/evo-earn/. The views expressed herein are those of the author(s) and do not necessarily reflect the views of the National Bureau of Economic Research.
\end{abstract}

(C) 2007 by Flavio Cunha and James J. Heckman. All rights reserved. Short sections of text, not to exceed two paragraphs, may be quoted without explicit permission provided that full credit, including (C) notice, is given to the source. 
The Evolution of Inequality, Heterogeneity and Uncertainty in Labor Earnings in the U.S.

Economy

Flavio Cunha and James J. Heckman

NBER Working Paper No. 13526

October 2007

JEL No. D3,J08

\begin{abstract}
A large empirical literature documents a rise in wage inequality in the American economy. It is silent on whether the increase in inequality is due to greater heterogeneity in the components of earnings that are predictable by agents or whether it is due to greater uncertainty faced by agents. Applying the methodology of Cunha, Heckman and Navarro (2005) to data on agents making schooling decisions in different economic environments, we join choice data with earnings data to estimate the fraction of future earnings that is forecastable and how this fraction has changed over time. We find that both predictable and unpredictable components of earnings have increased in recent years. The increase in uncertainty is substantially greater for unskilled workers. For less skilled workers, roughly $60 \%$ of the increase in wage variability is due to uncertainty. For more skilled workers, only $8 \%$ of the increase in wage variability is due to uncertainty. Roughly $26 \%$ of the increase in the variance of returns to schooling is due to increased uncertainty. Using conventional measures of income inequality masks the contribution of rising uncertainty to the rise in the inequality of earnings for less educated groups.
\end{abstract}

Flavio Cunha

University of Pennsylvania

Department of Economics

160 McNeil Building

3718 Locust Walk

Philadelphia PA 19104

fcunha@sas.upenn.edu

James J. Heckman

Department of Economics

The University of Chicago

1126 E. 59th Street

Chicago, IL 60637

and NBER

jjh@uchicago.edu 


\section{Introduction}

A large literature documents an increase in wage inequality in the American economy over the 1970's and 1980's (see Katz and Autor, 1999). This increase in wage inequality has occurred both within and between education-experience groups.

Cunha, Heckman, and Navarro (2005), henceforth CHN, note that variability in wages across people over time is not the same as uncertainty in wages. Some of the variability may be due to variability in predictable components observed by agents but not observed by the observing economist. CHN estimate that roughly half of all variability is due to uncertainty. They look at uncertainty at a point in time. In this paper, we apply their methodology to estimate how much of the recent increase in wage inequality is due to an increase in components predictable by the agents at the age they make their college attendance decisions and how much is due to components that are unpredictable at that age.

A large literature in empirical labor economics starting with the pioneering work of Friedman and Kuznets (1945) uses panel data to decompose earnings into permanent and transitory components. Using such statistical decompositions, Gottschalk and Moffitt (1994) document an increase in measured earnings instability in recent decades. The variance of transitory components greatly increases from the period 1970-1978 to the period 19791987. However, purely statistical decompositions cannot distinguish uncertainty from other sources of variability. Transitory components as measured by a statistical decomposition may be perfectly predictable by agents, partially predictable or totally unpredictable.

This paper uses cross-cohort data on schooling choices and future earnings to estimate the evolution of uncertainty in the labor market. We show that unforecastable components in labor income have increased in recent years, especially for less skilled workers. Our findings support the claim of Ljungqvist and Sargent (2004) that turbulence has increased in unskilled labor markets. This increase is not revealed in traditional measures of earnings inequality which do not distinguish between predictable and unpredictable components.

Our approach is based on the following simple idea. A decision variable $D_{1}$ determined 
in period 1, say consumption in the first period, may depend on outcomes $Y_{1}, \ldots, Y_{T}$ over horizon $T$ of another variable, say income, that is realized after the choice is taken. The correlation between $D_{1}$ and future $Y_{t}$ is a measure of how much of future $Y_{t}$ is known and acted on when agents make their choices about $D_{1}$.

When making their decisions, agents only imperfectly predict their future earnings using information $\mathcal{I}$. Suppose that $D_{1}$ depends on future $Y_{t}$ only through expected present value, $E(P V \mid \mathcal{I})$, where " $E$ " denotes expectation, $P V=\sum_{t=1}^{T} \frac{Y_{t}}{(1+\rho)^{t-1}}$, and $\rho$ is the discount rate. If, after the choice of $D_{1}$ is made, we actually observe $Y_{1}, \ldots, Y_{T}$, we can construct $P V$ ex post. If the information set is properly specified, the residual corresponding to the component of $P V$ that is not forecastable in the first period, $V=P V-E(P V \mid \mathcal{I})$, should not predict $D_{1} . E(P V \mid \mathcal{I})$ is predictable. $V$ is a measure of uncertainty. The variance in $P V$ that is unpredictable using $\mathcal{I}$ is a measure of uncertainty. ${ }^{1}$

This paper uses college attendance choices as $D_{1}$. Following Becker (1964), these choices depend on comparisons of earnings in the schooling level chosen and in alternative states. We must modify the simple test just described to account for the economist's inability to measure realized earnings in schooling states not selected that govern choice.

Using choice data combined with earnings data, we find that both predictable and unpredictable components of earnings variance have increased in recent years. The increase in uncertainty is microeconomic, and is much greater for unskilled workers. Macroeconomic uncertainty has decreased, especially for less skilled workers. For less skilled workers, roughly $60 \%$ of the increase in wage variability within schooling groups is due to uncertainty. For more skilled workers, only $8 \%$ of the increase in inequality is due to uncertainty. Roughly $26 \%$ of the increase in the variance of returns to schooling is due to increased uncertainty.

The rest of this paper is in five parts. Part 2 summarizes the model of CHN used to obtain our estimates. A web supplement presents semiparametric proofs of identification

\footnotetext{
${ }^{1}$ The Sims (1972) test for noncausality is based on a related idea in a linear prediction framework. Whereas Sims tests whether future $Y_{t}$ predict current $D_{1}$, we measure what fraction of future $Y_{t}$ predict current $D_{1}$ and use a more general prediction process.
} 
based on their work. Part 3 presents empirical results. Part 4 concludes.

\section{The CHN Model}

To identify the forecastable components of future earnings and how they have changed over time, we draw on the analysis of CHN, which we briefly summarize.

\subsection{Earnings Equations}

Using the Roy model (1951) and its generalizations, agents possess two ex post earnings streams, $\left(Y_{0, t}, Y_{1, t}\right), t=1, \ldots, T$, for schooling levels " 0 " and "1" respectively. They are assumed to have finite means. For conditioning variables $X$, we write:

$$
\begin{aligned}
& Y_{0, t}=X \beta_{0, t}+U_{0, t} \\
& Y_{1, t}=X \beta_{1, t}+U_{1, t}, \quad t=1, \ldots, T .
\end{aligned}
$$

The error terms $U_{s, t}$ are assumed to satisfy $E\left(U_{s, t} \mid X\right)=0, s=0,1^{2}$ Allowing for agespecific returns incorporates post-school investment as a determinant of earnings.

\subsection{Choice Equations}

The human capital model of Becker (1964) is based on present value income maximization. We extend that model by assuming that agents are risk neutral and make schooling choices based on expected present value income maximization given information set $\mathcal{I}$. Write the index $I$ of present values as

$$
I=E\left[\sum_{t=1}^{T}\left(\frac{1}{1+\rho}\right)^{t-1}\left(Y_{1, t}-Y_{0, t}\right)-C \mid \mathcal{I}\right]
$$

\footnotetext{
${ }^{2}$ Our analysis does not require linearity of the model in terms of parameters. See CHN. We use linearity because of its familiarity and simplicity.
} 
where $C$ is the cost of attending college. $Z$ and $U_{C}$ denote, respectively, the observable and unobservable determinants of costs. Assume that costs can be written as

$$
C=Z \gamma+U_{C}
$$

Defining

$$
\mu_{I}(X, Z)=\sum_{t=1}^{T}\left(\frac{1}{1+\rho}\right)^{t-1} X\left(\beta_{1, t}-\beta_{0, t}\right)-Z \gamma
$$

and

$$
U_{I}=\sum_{t=1}^{T}\left(\frac{1}{1+\rho}\right)^{t-1}\left(U_{1, t}-U_{0, t}\right)-U_{C}
$$

and substituting in (1), (2), and (4) into (3) we obtain

$$
I=E\left[\mu_{I}(X, Z)+U_{I} \mid \mathcal{I}\right]
$$

$E\left(U_{I} \mid \mathcal{I}\right)$ is the error term in the choice equation and it may or may not include $U_{1, t}, U_{0, t}$, or $U_{C}$, depending on what is in the agent's information set. Similarly, $\mu_{I}(X, Z)$ may only be based on expectations of future $X$ and $Z$ at the time schooling decisions are made. People go to college if the expected present value of earnings is positive:

$$
S=\mathbf{1}[I \geq 0] .
$$

\subsection{Test Score Equations}

In addition to data on earnings and choices, we also have access to data on a set of cognitive test score equations. Let $M_{k}$ denote the agent's score on the $k^{t h}$ test. Assume that the $M_{k}$ 
have finite means and can be expressed in terms of conditioning variables $X^{M}$. Write

$$
M_{k}=X^{M} \beta_{k}^{M}+U_{k}^{M} \text { and } E\left(U_{k}^{M} \mid X^{M}\right)=0, k=1,2, \ldots, K
$$

Both the decision to attend college and realized earnings likely depend on the cognitive skills that agents have at the time their schooling choices are made. Test scores facilitate but are not essential to our identification strategy.

\subsection{Heterogeneity and Uncertainty}

The earnings of agents of schooling level $s$ at age $t$ can be decomposed into predictable and unpredictable components

$$
Y_{s, t}=E\left(Y_{s, t} \mid \mathcal{I}\right)+V_{s, t}, \quad s=0,1, t=1, \ldots, T
$$

The component $E\left(Y_{s, t} \mid \mathcal{I}\right)$ is available to the agent to help make schooling choices. It is a component of realized earnings. The component $V_{s, t}$ does not enter the schooling equation because it is unknown at the time schooling decisions are made. However, it determines realized earnings.

To determine which components are in the information set of the agent, we need to determine which specification of the information set $\mathcal{I}$ best characterizes the dependence between schooling choices and future earnings. CHN use factor structure approximations to decompose earnings into predictable and unpredictable components. Other approximations might be used (see, e.g., MaCurdy, 1982, 2007) but factor structures are computationally and conceptually convenient and can approximate general error processes. The advantage of factor models is that they enable analysts to partition realized earnings into orthogonal components. Some of these components may be known by the agent when schooling choices are made and some components may not. By factor analyzing earnings and choice equations we can determine which components (factors) of realized earnings appear in the choice 
equations. To show this, following $\mathrm{CHN}$, we introduce an explicit factor structure for the disturbance terms, starting with the test score equations.

\subsection{Factor Models}

Break the error term $U_{k}^{M}$ in the test score equations into two components. The first component is a factor, $\theta_{1}$, that is common across all test score equations. The second component is unique to test score equation $k, \varepsilon_{k}^{M}$. In this notation, we can write equation (7) as

$$
M_{k}=X^{M} \beta_{k}^{M}+\theta_{1} \alpha_{k}^{M}+\varepsilon_{k}^{M}, k=1, \ldots, K
$$

where the $\alpha_{k}^{M}$ are "factor loadings", i.e. coefficients that map $\theta_{1}$ into $M_{k}$.

Following the psychometric literature, the factor $\theta_{1}$ might be interpreted as a latent cognitive ability which potentially affects all test scores but that interpretation is not essential to our analysis. We assume that $\theta_{1}$ is independent of $X^{M}$ and $\varepsilon_{k}^{M}$. The $\varepsilon_{k}^{M}$ are mutually independent and independent of $\theta_{1}$. Modeling test scores in this fashion allows them to be noisy measures of cognitive ability. ${ }^{3}$

\subsubsection{Earnings and Choice Equations}

We decompose the error terms in the earnings equations into factors and idiosyncratic errors. Let factors and factor loadings be $\theta=\left(\theta_{1}, \ldots, \theta_{K}\right)$ and $\alpha_{s, t}=\left(\alpha_{1, s, t}, \ldots, \alpha_{K, s, t}\right)$, respectively. The idiosyncratic error term, $\varepsilon_{s, t}$, affects only the period- $t$, schooling-s earnings equation. We assume that $U_{0, t}$ and $U_{1, t}$ can be written in factor-structure form

$$
U_{s, t}=\theta \alpha_{s, t}^{\prime}+\varepsilon_{s, t} \quad s=0,1, \quad t=1, \ldots, T .
$$

\footnotetext{
${ }^{3}$ Applying the analysis of Schennach (2004), identification of the model can be secured under much weaker conditions.
} 
We assume that factor components are mutually independent and independent of $X$ and $\varepsilon_{s, t}$ for all $s, t$. The $\varepsilon_{\ell, t}, \ell=0,1$ and $t=1, \ldots, T$, are mutually independent. The cost equation is decomposed in a fashion similar to the earnings equations, so that (4) can be rewritten as

$$
C=Z \gamma+\theta \alpha_{C}^{\prime}+\varepsilon_{C}
$$

where $\varepsilon_{C}$ is independent of $\theta, X, Z, \varepsilon_{s, t}, s=0,1, t=1, \ldots, T$. Given the factor representation (9) and (10), we can represent the choice index $I$ for schooling as

$$
I=E\left[\sum_{t=1}^{T}\left(\frac{1}{1+\rho}\right)^{t-1} X\left(\beta_{1, t}-\beta_{0, t}\right)-Z \gamma+\theta \alpha_{I}^{\prime}+\sum_{t=1}^{T}\left(\frac{1}{1+\rho}\right)^{t-1}\left(\varepsilon_{1, t}-\varepsilon_{0, t}\right)-\varepsilon_{C} \mid \mathcal{I}\right]
$$

where we define

$$
\alpha_{I}=\sum_{t=1}^{T} \frac{1}{(1+\rho)^{t-1}}\left(\alpha_{1, t}-\alpha_{0, t}\right)-\alpha_{C} .
$$

\subsection{The Estimation of Predictable Components of Future Earn- ings}

We now illustrate how to apply the method of CHN to determine which components of realized earnings are known to the agent when schooling choices are made. For expositional simplicity, in this section alone we assume that $X, Z, \beta_{s, t}(s=0,1, t=1, \ldots, T)$ and $\varepsilon_{C}$ are in the information set $\mathcal{I}$. ${ }^{4}$ To fix ideas, suppose that there are two factors, $\theta_{1}$ and $\theta_{2}$. In our empirical work reported below we use more factors.

Suppose that it is claimed that both $\theta_{1}$ and $\theta_{2}$ are known by the agent when schooling choices are made but the $\varepsilon_{s, t}$ are not, i.e. $\left\{\theta_{1}, \theta_{2}\right\} \subset \mathcal{I}$, but $\varepsilon_{s, t} \notin \mathcal{I}$. If this is true, the index function governing schooling choices is

$$
I=\mu_{I}(X, Z)+\alpha_{1, I} \theta_{1}+\alpha_{2, I} \theta_{2}+\varepsilon_{C}
$$

\footnotetext{
${ }^{4}$ In our empirical analysis, we test for the presence or absence of ex post observables in $X$ that are in $e x$ ante information sets.
} 
Using standard results in discrete choice analysis (see Matzkin, 1992, for precise conditions), we can proceed as if we observed $I$ in equations (6) and (12) up to an unknown positive scale, i.e., from the discrete choices on schooling we observe the index generating the choices up to scale. From the correlation between $S$ and realized incomes, we can identify (up to scale) the covariance between $I$ and $Y_{s, t}, t=1, \ldots, T$ for $s=0$ or 1 . Conditional on $X, Z$ this covariance is

$$
\operatorname{Cov}\left(I, Y_{s, t} \mid X, Z\right)=\alpha_{1, I} \alpha_{1, s, t} \sigma_{\theta_{1}}^{2}+\alpha_{2, I} \alpha_{2, s, t} \sigma_{\theta_{2}}^{2}, s=0,1
$$

If $\theta_{2}$ is not known, or is known and not acted on by the agent when schooling choices are made, $\alpha_{2, I}=0$. If neither $\theta_{2}$ nor $\theta_{1}$ is known, or acted on, by the agent, $\alpha_{1, I}=\alpha_{2, I}=0$.

Extending standard results in factor analysis, CHN show how to use test score data and earnings data to identify the factor loadings and the distribution of the factors in test score and earnings equations (8), (9) and (10) using self-selected samples. ${ }^{5}$ Self selection arises because analysts only observe the earnings stream associated with $s$ for persons who choose s. CHN establish conditions for identifying $\sigma_{\theta_{1}}^{2}, \sigma_{\theta_{2}}^{2}, \alpha_{1, s, t}$ and $\alpha_{2, s, t} s=0,1, t=1, \ldots, T$. We review their conditions in our web appendix. ${ }^{6}$

Putting these ingredients together, we can determine which components (factors) that determine realized $Y_{s, t}, s=0,1, t=1, \ldots, T$ are correlated with $I$. If component (factor) $\theta_{1}$ is correlated with $I$ and is acted on by the agent in making schooling choices, then $\alpha_{1, I} \neq 0$. If component $\theta_{2}$ is uncorrelated with $I$, then $\alpha_{2, I}=0$ and $\theta_{2}$ is not acted on by the agent in making schooling choices. ${ }^{7}$

\footnotetext{
${ }^{5}$ In our web supplement, we restate their formal proofs of identification. They identify the distributions of factors nonparametrically. Test score data are not required to secure identification. See, e.g., Heckman, Lochner, and Todd (2006).

${ }^{6}$ See Part III of the web supplement.

${ }^{7} \mathrm{CHN}$ interpret the factor loadings in the earnings equations as prices of unobserved skills that they interpret as factors. In this paper we do not adopt their interpretation. We allow agents to be uncertain about their future skills, future prices, or both. We interpret the factor loadings as convenient statistical devices for representing the components of realized earnings no matter what their source. Thus we do not maintain the perfect foresight assumption about future skill prices used by CHN.
} 


\section{Empirical Results}

In order to study the evolution of uncertainty and inequality in labor earnings in the U.S. economy, we analyze and compare two demographically comparable, temporally separated samples. We study white males born between 1957 and 1964, sampled by the National Longitudinal Survey of Youth (NLSY/1979). ${ }^{8}$ We also study an earlier sample of white males born between 1941 and 1952, surveyed in the National Longitudinal Survey (NLS/1966). ${ }^{9}$ In what follows, we refer to the samples as NLSY/1979 and NLS/1966, respectively. These data are described in detail in the data web appendix. ${ }^{10}$ Because we analyze only white males, we do not present a comprehensive investigation of the rise of inequality in the U.S. coming all within-group and between-group comparisons. However, we can abstract from influences that operate differentially on various demographic groups and focus on the rise of inequality that is due to forecastable versus unforecastable components. ${ }^{11}$

We analyze two schooling choices: high school and college graduation. Use $s=0$ to denote those who stop at high school and $s=1$ to denote those who graduate college. The Web Data Appendix Tables I-1 and I-2 present descriptive statistics on the NLSY/1979 and NLS/1966 samples, respectively. In both samples, college graduates have higher test scores, fewer siblings and parents with higher levels of education than those who stop at high school. In the NLSY/1979, college graduates are more likely to live in locations where the tuition for four-year college is lower. This is not true for the college graduates in NLS/1966. ${ }^{12}$

We analyze the evolution of labor income from ages 22 to 36. For the NLS/1966 sample,

\footnotetext{
${ }^{8}$ See Miller (2004) for a description of the NLSY data.

${ }^{9}$ See documentation at http://www.nlsinfo.org/web-investigator/docs.php?mychrt=boys for a description of the NLS data.

${ }^{10} \mathrm{http} / / /$ jenni.uchicago.edu/evo-earn/. The Web Appendix has five parts: Web Supplement I contains a description of the samples; Web Supplement II presents a description of the estimated model, including the goodness of fit tests; Web Supplement III provides a thorough review on the identification of the model; Web Supplement IV discusses the estimates of the joint distribution of outcomes; Web Supplement V presents the results of the schooling choice on our measures of aggregate inequality.

${ }^{11}$ See Katz and Autor (1999) for a discussion of other factors contributing to the observed rise in wage inequality.

${ }^{12}$ See Cameron and Heckman (2001) for details on the construction of the tuition variables used in this paper.
} 
reliable data are not available after that age. Figures 1 and 2 display, respectively, the mean earnings by age of high school and college graduates for NLSY/1979 and NLS/1966. ${ }^{13}$ In both data sets, college graduates start off with lower mean labor income than high-school graduates but overtake them. This is consistent with earlier evidence by Mincer (1974). We plot the standard deviation of earnings by age for high school (Figure 3) and college (Figure 4) graduates for both cohorts. The standard deviation of earnings increases with age for high school and college graduates in both data sets. The standard deviation of earnings by age is uniformly greater in the later cohort, for both high school and college graduates.

Both data sets have measures of cognitive test scores. ${ }^{14}$ For the NLSY/1979, we use five components of the ASVAB test battery: arithmetic reasoning, word knowledge, paragraph comprehension, math knowledge and coding speed. We dedicate the first factor $\left(\theta_{1}\right)$ to this test system, and exclude other factors from it. Thus $\theta_{1}$ is a measure of cognitive ability.

In the NLS/1966 there are many different achievement tests, but in our empirical work we use the two most commonly reported ones: the OTIS/BETA/GAMMA and the California Test of Mental Maturity (CTMM). One problem with the NLS/1966 sample is that there are no respondents for whom we observe scores from two or more achievement tests. That is, for each respondent we observe at most one test score. We supplement the information from these test scores by using additional proxies for cognitive achievement. ${ }^{15}$

We model the test score $j, M_{j}$ by equation (8). The covariates $X^{M}$ include family

\footnotetext{
${ }^{13}$ Earnings figures are adjusted for inflation using the CPI and we take the year 2000 as the base year.

${ }^{14} M$ in the notation of section 2 .

${ }^{15}$ We use information from three different tests from the "Knowledge of the World of Work" survey. The first is a question regarding occupation: the respondent is asked about the duties of a given profession, say draftsman. For this specific example, there are three possible answers: (a) makes scale drawings of products or equipment for engineering or manufacturing purposes, (b) mixes and serves drinks in a bar or tavern, (c) pushes or pulls a cart in a factory or warehouse. The second test is a test that asks for each occupation in the first test, the level of education associated with that occupation. The third test is an earnings comparison test. Specifically, it asks the respondent who he/she believes makes more in a year, comparing two different occupations. In Web Data Appendix Table I-3 we show that even after controlling for parental education, number of siblings, urban residence at age 14, and dummies for year of birth, the "Knowledge of the World of Work" test scores are correlated with the cognitive test scores. The correlation with OTIS/BETA/GAMMA and CTMM is stronger for the occupation and education tests than for the earnings-comparison test.
} 
background variables, year of birth dummies, and characteristics of the individuals at the time of the test. ${ }^{16}$ To set the scale of $\theta_{1}$, we normalize $\alpha_{1}^{M}=1$. Using factor models instead of working directly with test scores, recognizes that test scores may be noisy measures of cognitive skills.

Salient features of our data are presented in Table 1. Fewer males graduate college in the later cohort. This is consistent with a large body of evidence that shows enhanced college participation in earlier cohorts to avoid the Vietnam War draft. ${ }^{17}$ For a variety of specifications, Mincer returns increase for the later cohorts. This is consistent with a large body of evidence on the returns to schooling (Katz and Autor, 1999).

Qualitatively similar models characterize both samples. For both cohorts, a three factor model is sufficient to fit the data on ex post earnings, test scores and schooling choice. ${ }^{18}$ The identification of the model requires the normalization of some factor loadings because the scale of $\theta$ is otherwise indeterminate. Web Supplement Appendix Table II-1 shows the factor loading normalizations imposed in both data sets. In both samples, the covariates $X$ are urban residence at age 14, year effects, and an intercept.

The covariates $Z$ in the cost function are urban residence at age 14, dummies for year of birth, and variables that affect the costs of going to college but do not affect outcomes $Y_{s, t}$ after controlling for ability, such as mother's education, father's education, number of siblings, and local tuition. ${ }^{19}$ Because in both samples we only have earnings data into the middle 30s, the truncated discounted earnings after the periods of observation (denoted $\left.t=1, \ldots, T^{*}\right)$ are absorbed into the definition of expected $C$ in equation (3). Thus $C$

\footnotetext{
${ }^{16}$ In our analyses of both the NLSY/1979 and NLS/1966 data we include mother's education, father's education, number of siblings, urban residence at age 14, dummies for year effects and an intercept. In the NLSY/1979 sample we also control for whether the test taker is enrolled in school and the highest grade completed at the time of the test. In the NLS/1966 all of the respondents were enrolled in school at the time of the test (in fact, the test score is obtained in a survey from schools). We do not know the highest grade completed at the time of the test for the NLS/1966 sample.

${ }^{17}$ See e.g. Heckman and LaFontaine (2007)

${ }^{18}$ In the next subsection and at our website, we discuss the goodness-of-fit measures used to select the appropriate model for each sample.

${ }^{19}$ Because we control for ability and other unobservables captured by the factors, our parsimonious specification of the earnings equations is less controversial.
} 
estimated from the choice equation is not a pure measure of costs. We discuss this further in Section 3.3.

Each factor $\theta_{k}$ is assumed to be generated by a mixture of $J_{k}$ normal distributions,

$$
\theta_{k} \sim \sum_{j=1}^{J_{k}} p_{k, j} \phi\left(\theta_{k} \mid \mu_{k, j}, \lambda_{k, j}\right)
$$

where $\phi\left(\eta \mid \mu_{j}, \lambda_{j}\right)$ is a normal density for $\eta$ with mean $\mu_{j}$ and variance $\lambda_{j}$ and $\sum_{j=1}^{J_{k}} p_{k, j}=1$, and $p_{k, j}>0 .^{20}$ The $\varepsilon_{s, t}$ are also assumed to be generated by mixtures of normals. We estimate the model using Markov Chain Monte Carlo methods as described in Carneiro, Hansen, and Heckman (2003). For all factors, a four-component model $\left(J_{k}=4, k=1, \ldots, 3\right)$ is adequate. For all $\varepsilon_{s, t}$ we use a three-component model. ${ }^{21}$

The dependent variable in our analysis is earnings and not log earnings. Under risk neutrality, agents act on expected earnings. The traditional argument for fitting log earnings is based on goodness of fit considerations. ${ }^{22}$ Using a nonparametric estimation method for determining the error distribution, our model fits the earnings data.

\subsection{How the model fits the data}

Figure 5 compares actual and predicted densities of earnings at age 33 for the overall sample for the NLSY/1979. The fit is good overall and in subsamples disaggregated by education and for all of the other age groups. ${ }^{23}$ When we perform formal tests of equality of predicted versus actual densities, we pass these tests within schooling groups for most ages. ${ }^{24}$ The model fits the NLS/1966 data marginally better than it fits the NLSY/1979 data. The

\footnotetext{
${ }^{20}$ Ferguson (1983) shows that mixtures of normals with a large number of components approximate any distribution of $\theta_{k}$ arbitrarily well in the $\ell^{1}$ norm.

${ }^{21}$ Additional components do not improve the goodness of fit of the model to the data.

${ }^{22}$ See Heckman and Polachek (1974).

${ }^{23}$ The Web Supplement Appendix shows fits for all ages. See Web Supplement Appendix Figures II-1.1 through II-3.30 for the overall, high-school, and college earnings, for both the NLSY/1979 and NLS/1966.

${ }^{24}$ See Web Supplement Appendix Table II-2.
} 
estimated factor distributions are non-normal. ${ }^{25}$ Our tests reveal that agents know $\theta_{1}$ and $\theta_{2}$ but not $\theta_{3}$ at the time that they make their schooling decisions. Thus the third factor is revealed after schooling choices are made. In addition, they do not know the $\varepsilon_{s, t}, s=0,1$, $t=1, \ldots, T^{*}$, or the year dummies in the earnings equations.

\subsection{The Evolution of Joint Distributions of Earnings and the Re- turns to College}

A standard approach to estimating the distribution of earnings in counterfactual schooling states (e.g., the distributions of college earnings for people who choose to be high school graduates under a particular policy regime) assumes that college and high school distributions are the same except for an additive constant — the coefficient of a schooling dummy in an earnings regression conditioned on covariates. Using the methods developed in CHN and reviewed in Part III of the web supplement, we can identify both ex ante and ex post joint distributions without making this strong assumption or the other strong assumptions conventionally used to identify joint distributions of counterfactuals. ${ }^{26}$ We discuss our estimates of ex ante and ex post joint distributions in Web Appendix IV.

Knowledge of the joint distributions allows analysts to compare factual with counterfactual distributions. Take agents who choose to be high-school graduates. We can compare the density of the present value of truncated ex post earnings in the high-school sector with the density of the truncated present value of earnings in the college sector earnings for the high-school graduates. Both densities are plotted in Figures 6A and 6B for the NLSY/1979 and NLS/1966, respectively. For both data sets, the high-school attenders would have higher earnings if they had chosen to be college graduates. For college graduates, we compare the actual density of present value of truncated earnings in the college sector with that in the

\footnotetext{
${ }^{25}$ Figures II-5.1-5.6 plot the estimated densities of the factors for the NLS 1966 and 1979 NLSY samples by attained schooling level.

${ }^{26}$ Abbring and Heckman (2007) discuss a variety of alternative assumptions used to identify joint counterfactual distributions, including the work of CHN on which we draw.
} 
high-school sector. We display these densities in Figures 7A and 7B for the NLSY/1979 and NLS/1966, respectively. Again, in both data sets the densities of high-school truncated present value of earnings is to the left of the college density.

From such distributions, we can generate the distribution of ex post gross rate of return $R$ to college (excluding costs) as $R=\frac{Y_{1}-Y_{0}}{Y_{0}} \cdot{ }^{27}$ The typical high school student would have annual gross returns of around $6 \%$ for a college education in the earlier cohort and around 9.5\% for the later cohort. (See Table 2.) For the typical college graduate, the annual return is around $8.7 \%$ for the earlier cohort and $13.5 \%$ for the later cohort. For individuals at the margin, these figures are $7.5 \%$ and $11.8 \%$ respectively.

\subsection{The Evolution of Uncertainty and Heterogeneity}

Under risk neutrality, the valuation or net utility function for schooling is

$$
I=E\left(\sum_{t=1}^{T^{*}} \frac{Y_{1, t}-Y_{0, t}}{(1+\rho)^{t-1}} \mid \mathcal{I}\right)-E\left(C_{T^{*}} \mid \mathcal{I}\right)
$$

where

$$
C_{T^{*}}=-\sum_{t=T^{*}+1}^{\bar{T}} \frac{1}{(1+\rho)^{t-1}}\left(Y_{1, t}-Y_{0, t}\right)+C .
$$

Because of the truncation of lifetime earnings in our data, the estimated cost includes a component due to the expected return realized after period $T^{*}$. Individuals go to college if $I>0$. As previously explained, the correlation between schooling choices and realized future income allows the analyst to disentangle predictable components from uncertainty. For both cohorts, we test, and do not reject, the hypothesis that, at the time they make college going decisions, individuals know their $Z$ and the factors $\theta_{1}$ and $\theta_{2}$. They do not know the time dummies (year effects) in $X$ and the factor $\theta_{3}$ or $\varepsilon_{s, t}, s=0,1, t=1, \ldots, T^{*}$, at the time they make their educational choices. We now explore the implications of our estimates for the growth of uncertainty in the American economy.

\footnotetext{
${ }^{27}$ See Web Appendix II-4.1-4.8 for plots of the densities of returns and costs.
} 


\subsubsection{Total Residual Variance and Variance of Unforecastable Components}

The unforecastable component of the residual is the sum of the components that are not in the information set of the agent at the time schooling choices are made. For both data sets, the unforecastable component of the present value of earnings estimates up to age $T^{*}$ is

$$
P_{s}=\sum_{t=1}^{T^{*}} \frac{\theta_{3} \alpha_{3, s, t}+\mathcal{T}_{t} \phi+\varepsilon_{s, t}}{(1+\rho)^{t-1}}
$$

where the $\mathcal{T}_{t}$ are the year dummies in the future earnings equation that we estimate to be unknown to agents at the time they make their schooling choices. The variance of the unforecastable component in the present value of earnings up to age $T^{*}$ for schooling level $s$ is $\operatorname{Var}\left(P_{s}\right)$.

Table 3 displays the total variance and the variance of the unforecastable components for each schooling level for both NLS/1966 and NLSY/1979. Total variance of the present value of earnings up to age $T^{*}$ increases from 195.9 (NLS/1966) to 292.4 (NLSY/1979). This implies an increase of almost $50 \%$ in the total variance. The increase is smaller for the variance of the present value of high school earnings up to age 36: it goes from 137 in NLS/1966 to 165, an increase of almost $21 \%$.

The variance of the unforecastable components up to age 36 has also increased. For college earnings, it is 76.3 in the early cohort and becomes 84.4 in the more recent cohort. For high school earnings, it is 31.6 in the NLS/1966 and becomes 48.1 in the NLSY/1979. In percentage terms, this implies that the variance of the unforecastable component increased $10.6 \%$ for college and $52 \%$ for high school. Table 3 shows that total variance in the present value of gross returns to college up to age 36 increased from 611 in NLS/1966 to 823 in NLSY/1979, an increase of about 35\%. The variance of the unforecastable components increased from 167 to 222 , or roughly $33 \%$.

The increase in the variance of the unforecastable components of earnings is a key element in explaining the increase in the total variance in earnings for high school graduates. It is 
much less of a driving force in explaining the increase in the variance of college earnings.

Figures 9A and 9B plot the densities of realized and unforecastable high-school earnings for the 1979 and 1966 samples, respectively. Figures 10A and 10B make the analogous comparison for college earnings for the 1979 and 1966 samples, respectively. Finally, Figures 11A and 11B show the corresponding figures for returns. Unforecastable components are a major component of total earnings variance.

Table 3 also presents the total variance and the variance of forecastable components for each schooling level for both NLS/1966 and NLSY/1979. In the recent cohort, individuals who attend college have become more diverse in predictable ways possibly associated with greater possibilities for specialization in the modern economy. There is only a small change in the predictability of high school earnings. For college earnings, the variance of forecastable components is 119.5 for the NLS/1966 and 207.9 for the NLSY/1979 corresponding to a $74 \%$

increase. For high school earnings, it is 105 for the NLS/1966 and 117.2 for the NLSY/1979, which implies an increase of only 11\%. There is a substantial increase in the variance of predictable returns to college for the more recent cohort.

In summary, this analysis shows that about $8 \%$ of the increase in the variability in college earnings, $60 \%$ of the increase in the variability in high school earnings, and about $26 \%$ of the increase in the variability of gross returns to college is due to an increase in uncertainty in the American labor market. We next turn to an analysis of how the increase in variance is apportioned by age.

\subsubsection{The Variance of the Unforecastable and Forecastable Components by Age}

The increase in uncertainty is not uniform across age groups. Figure 12A plots the variances of unforecastable components by age in high school earnings in NLS/1966, and NLSY/1979. They are flat until age 27/28. A similar pattern characterizes college earnings (Figure 12B). After age 27/28, college and high school variances in both cohorts increase with age. Until age 36 the NLSY/1979 cohort experiences a much more rapid increase in variances with 
age than does the NLS/1966 cohort. The college sample shows a similar flat and identical pattern until age 27. Again, components due to uncertainty increase with age but the only divergence between the younger cohort and the older cohort is in the 28-31 age range.

The age profile of the variance of forecastable components is different. (See Figures 13A and 13B.) For both college and high school graduates it rises up to age 27 and then declines somewhat. For high school graduates, the increase is greater for the more recent cohort up to age 27 but then the two curves coincide. For college graduates, the predictable components of variance are uniformly higher at each age for the more recent cohort.

\subsubsection{Accounting for Macro Uncertainty}

The literature in macroeconomics documents that aggregate instability has decreased in the past 30 years (see Gordon, 2005). To capture reduced macro uncertainty, we have introduced time dummies into the earnings equation. ${ }^{28}$ Our tests indicate that the time dummies in the ex post earnings equations do not enter the schooling choice equation. Thus, we estimate that macro uncertainty is not forecastable by agents at the time schooling choices are made. Macro uncertainty decreased by $90 \%$ for later cohorts of high school educated workers (see Table 4). Macro shocks have decreased slightly if at all for college educated workers. These estimates are consistent with the evidence that US business cycle volatility has decreased in recent years. At the same time, macro uncertainty is a tiny fraction of total uncertainty for both $\operatorname{cohorts}(6.8 \%$ for $1966,3.3 \%$ for 1979$)$.

\subsubsection{Inequality Accounting}

In deriving the estimates presented in this paper, we have assumed risk neutrality and/or full insurance against all shocks. It would be informative to estimate a more general model with risk aversion by agents explicitly modeled. Introducing risk aversion and market structure

\footnotetext{
${ }^{28}$ We face the standard problem of the lack of simultaneous identification of age, period and cohort effects so we cannot identify cohort effects in the presence of age and time effects. Thus our estimates of uncertainty of time effects can also be interpreted as estimates of uncertainty of cohort effects. See Heckman and Robb (1985) for a discussion of this problem and a discussion of the interactions that can be identified.
} 
raises a more general set of questions about the identification of the model discussed in CHN. ${ }^{29}$ Navarro (2007) reports estimates of a related model with risk aversion.

Instead of estimating a model with risk aversion, in this paper we draw on a large literature on inequality measurement that evaluates alternative distributions of earnings using a variety of indices and social welfare functions. ${ }^{30}$ These criteria embody social preferences toward inequality aversion. We contribute to this literature by distinguishing the contributions to inequality arising from uncertainty and the contributions arising from predictable components, which we term heterogeneity. These are measured with respect to information sets at the college going age.

We simulate the distribution of the observed present value of truncated earnings for which we compute the Gini coefficient, the Theil Entropy Index, and the Atkinson Index under different scenarios. For each cohort $k$, we write earnings of individual $i$ at the time $t$, schooling level $s$ as $Y_{k, i, t}$. Let $S_{k, i}=1$ if a person graduates college and $S_{k, i}=0$ if a person graduates high school. We may write

$$
Y_{k, i, t}=S_{k, i} Y_{k, 1, i, t}+\left(1-S_{k, i}\right) Y_{k, 0, i, t}
$$

\footnotetext{
${ }^{29}$ A basic question first posed by CHN (2005) is "What can be identified in more general environments?" In the absence of perfect certainty or perfect risk sharing, preferences and market environments also determine schooling choices. The separation theorem used in this paper that allows consumption and schooling decisions to be analyzed in isolation of each other breaks down.

If we postulate information arrival processes a priori, and assume that preferences are known up to some unknown parameters as in Flavin (1981), Blundell and Preston (1998) and Blundell, Pistaferri, and Preston (2004), we can identify departures from specified market structures. Flavin (1981), Blundell and Preston (1998) and Blundell, Pistaferri, and Preston (2002) specify explicit time series processes for the unobservables (e.g., ARMA or fixed effect/AR-1 models) with unknown coefficients but prespecified serial correlation structures and assume that the innovations in these processes are the uncertainty components while the predictable components are heterogeneity. Hansen (1987) shows a fundamental nonidentification result for the Flavin model estimated on aggregate data. Our use of micro panel data circumvents the problem he raises. An open question, not yet fully resolved in the literature, is how far one can go in nonparametrically jointly identifying preferences, market structures and agent information sets. One can add consumption data to the schooling choice and earnings data to secure identification of risk preference parameters (within a parametric family) and information sets, and to test among alternative models for market environments. Navarro (2007) attempts to do this. Alternative assumptions about what analysts know produce different interpretations of the same evidence. The lack of full insurance interpretation given to the empirical analysis by Flavin (1981) and Blundell, Pistaferri, and Preston (2004), may instead be a consequence of their misspecification of the generating processes of agent information sets.

${ }^{30}$ See Anand (1983), Foster and Sen (1997), Sen (2000), Atkinson and Bourguignon (2000) and Cowell (2000) for surveys of this literature.
} 
and

$$
Y_{k, i}=\sum_{t=1}^{T^{*}} \frac{Y_{k, i, t}}{(1+\rho)^{t-1}} .
$$

We show that the distribution of $Y_{k, i}$ for each cohort, displayed in the first row of Table $5 \mathrm{~A}$ (for the Gini index), Table 5B (for the Theil index) and Table 5C (for the Atkinson index), the NLSY/1979 cohort is more unequal than the NLS/1966 cohort under any inequality measurement we use. The Gini coefficient (Table 5A) grows by $16 \%$ from the earlier cohort to the later cohort. ${ }^{31}$ Table 5B shows that the Theil Entropy Index T grew by $38 \%$ from the NLS/1966 to the NLSY/1979. One of the advantages of the Theil Index is that it can be used to decompose overall inequality within and between schooling groups. Within inequality grew by $28 \%$ and between inequality grew by $450 \%$.

An explicit social welfare approach to measuring earnings inequality proceeds by constructing indexes based on social welfare functions defined over earnings distribution (see Cowell, 2000; Foster and Sen, 1997). ${ }^{32}$ For each cohort $k$, let $\mu_{k}$ denote the average income level computed over incomes of agents $i$ in all schooling groups,

$$
\mu_{k}=\frac{1}{n_{k}} \sum_{i=1}^{n_{k}} Y_{k, i}
$$

where $n_{k}$ is the number of persons in our samples of cohort $k$. Given a social welfare function $U\left(Y_{k, i}\right)$, the Atkinson index (1970) is defined as the per-capita level of present value of income $\bar{Y}_{k}$ such that, if equally distributed, would generate the same level of social welfare as the distribution of earnings in cohort $k$. That is, $\bar{Y}_{k}$ satisfies:

$$
\frac{\left(\bar{Y}_{k}\right)^{1-\epsilon}-1}{1-\epsilon}=\frac{1}{n_{k}} \sum_{i=1}^{n_{k}} \frac{Y_{k, i}^{1-\epsilon}-1}{1-\epsilon} .
$$

The parameter $\epsilon$ is a measure of inequality aversion $(\epsilon=0$ corresponds to no inequality

\footnotetext{
${ }^{31}$ The low level of the Gini coefficient arises from the averaging of incomes that arises in constructing present values, because we study of white males only, and from the truncation of the present value term due to data limitations.

${ }^{32}$ Anand (1983) presents a useful summary of the indices used in this literature.
} 
aversion; $\epsilon \rightarrow-\infty$ corresponds to Rawlsian inequality aversion). The Atkinson index $A$ is defined as:

$$
A=1-\left(\frac{\bar{Y}_{k}}{\mu_{k}}\right) .
$$

Table 5C computes the Atkinson Index for each cohort and its growth, for different values of inequality aversion parameter $\epsilon$. Regardless of the value of $\epsilon$, inequality has increased by between $40 \%$ to $60 \%$ according to the Atkinson Index.

Our previous analysis established that some portion of the inequality in observed present value of earnings is predictable at the age college decisions are made by the information in $\mathcal{I}$. We can compare the inequality that is produced by predictable factors (heterogeneity) versus overall earnings inequality. This allows us to determine the contribution of uncertainty to overall inequality using a variety of measures. We simulate counterfactual economies in which uncertainty is eliminated. Eliminating uncertainty can be accomplished by simulating an economy in which the unforecastable components are set at their means. We can keep schooling choices fixed at their values in the factual economy or allow agents to re-optimize and see how that affects inequality measurement. We do both, but differences arising from re-optimized schooling choice are of second order. See the tables in Appendix V (Tables V-A, $\mathrm{V}-\mathrm{B}$ and $\mathrm{V}-\mathrm{C}$, respectively). In the text, we report results holding schooling fixed at their value in the factual economy.

The second row of Table 5A presents the Gini coefficient for the economy without uncertainty in future earnings fixing schooling choices as in the factual economy. In this case, the Gini coefficient for the NLS/1966 would be 0.16 and for the NLSY/1979 would be 0.18, which represents a growth of less than $15 \%$ in inequality as measured by the Gini coefficient. The analogous calculation for the Theil index reported in Table 5B shows that the Overall Theil Index would have grown only by $34 \%$ if uncertainty were eliminated, while the Within and Between Theil Indexes would have grown by $22 \%$ and $394 \%$, respectively. The analogous exercise for the Atkinson index predicts an increase between 35\% and 42\%. (See Table 5C .)

These calculations show that rising inequality in the aggregate as measured by conven- 
tional inequality indices is largely driven by rising heterogeneity. However, as documented

in Table 3, there are sharp differences in the contribution of rising uncertainty to inequality for different schooling groups. High school graduates' earnings variability is due to a substantial rise in inequality due to uncertainty. Uncertainty in college graduate earnings has not increased substantially, although predictable components have become more variable.

\section{Summary and Conclusion}

This paper investigates the sources of rising wage inequality in the US labor market for white males. We find that increasing inequality arises both from increasing micro uncertainty and increasing heterogeneity that is predictable by agents. The latter could arise from increased specialization in labor markets, but we present no direct evidence on this question. Both predictable and unpredictable components have increased since the late 1960s. The fraction of the variability due to micro uncertainty has increased especially for less skilled workers. Aggregate uncertainty has decreased especially for unskilled workers. The recent increase in uncertainty has microeconomic origins. Our evidence of substantially increased uncertainty at the micro level for recent cohorts of unskilled labor supports the increased turbulence hypothesis of Ljungqvist and Sargent (2004). Conventional measures of aggregate inequality do not reveal the substantial contribution of the rise in the uncertainty of the earnings of less skilled workers to their observed rise in the inequality of their earnings. 


\section{References}

Abbring, J. H. and J. J. Heckman (2007). Econometric evaluation of social programs, part III: Distributional treatment effects, dynamic treatment effects, dynamic discrete choice, and general equilibrium policy evaluation. In J. Heckman and E. Leamer (Eds.), Handbook of Econometrics, Volume 6B. Amsterdam: Elsevier. Forthcoming.

Anand, S. (1983). Inequality and Poverty in Malaysia: Measurement and Decomposition. New York: Published for the World Bank by Oxford University Press.

Atkinson, A. B. (1970, September). On the measurement of inequality. Journal of Economic Theory 2(3), 244-266.

Atkinson, A. B. and F. Bourguignon (2000). Introduction: Income distribution and economics. In A. B. Atkinson and F. Bourguignon (Eds.), Handbook of Income Distribution, Volume 1, pp. 1-58. Amsterdam: North-Holland.

Becker, G. S. (1964). Human Capital: A Theoretical and Empirical Analysis, with Special Reference to Education. New York: National Bureau of Economic Research, distributed by Columbia University Press.

Blundell, R., L. Pistaferri, and I. Preston (2002). Partial insurance, information and consumption dynamics. Technical Report IFS Working Papers: W02/16, Institute for Fiscal Studies, London.

Blundell, R., L. Pistaferri, and I. Preston (2004, October). Consumption inequality and partial insurance. Technical Report WP04/28, Institute for Fiscal Studies.

Blundell, R. and I. Preston (1998, May). Consumption inequality and income uncertainty. Quarterly Journal of Economics 113(2), 603-640.

Cameron, S. V. and J. J. Heckman (2001, June). The dynamics of educational attainment for black, hispanic, and white males. Journal of Political Economy 109(3), 455-99. 
Carneiro, P., K. Hansen, and J. J. Heckman (2003, May). Estimating distributions of treatment effects with an application to the returns to schooling and measurement of the effects of uncertainty on college choice. International Economic Review 44 (2), 361-422.

Cowell, F. A. (2000). Measurement of inequality. In A. B. Atkinson and F. Bourguignon (Eds.), Handbook of Income Distribution, Volume 1, pp. 87-166. Amsterdam: NorthHolland.

Cunha, F., J. J. Heckman, and S. Navarro (2005, April). Separating uncertainty from heterogeneity in life cycle earnings, The 2004 Hicks Lecture. Oxford Economic Papers 57(2), $191-261$.

Ferguson, T. S. (1983). Bayesian density estimation by mixtures of normal distributions. In H. Chernoff, M. Rizvi, J. Rustagi, and D. Siegmund (Eds.), Recent Advances in Statistics: Papers in Honor of Herman Chernoff on his Sixtieth Birthday, pp. 287-302. New York: Academic Press.

Flavin, M. A. (1981, October). The adjustment of consumption to changing expectations about future income. Journal of Political Economy 89(5), 974-1009.

Foster, J. E. and A. K. Sen (1997). On Economic Inequality. New York: Oxford University Press.

Friedman, M. and S. S. Kuznets (1945). Income from Independent Professional Practice. New York: National Bureau of Economic Research.

Gordon, R. J. (2005). What caused the decline in U. S. business cycle volatility? In C. Kent and D. Norman (Eds.), The Changing Nature of the Business Cycle, pp. 61-104. Sydney, Australia: Economics Group, Reserve Bank of Australia. Proceedings of a conference held at the H.C. Coombs Centre for Financial Studies, Kirribilli, Australia on 11-12 July 2005. 
Gottschalk, P. and R. Moffitt (1994). The growth of earnings instability in the U.S. labor market. Brookings Papers on Economic Activity 2, 217-254.

Hansen, L. P. (1987). Calculating asset prices in three example economies. In T. F. Bewley (Ed.), Advances in Econometrics: Fifth World Congress, Volume 1, pp. 207-243. New York: Cambridge University Press.

Heckman, J. J. and P. A. LaFontaine (2007). The American high school graduation rate: Trends and levels. Unpublished manuscript, University of Chicago, Department of Economics.

Heckman, J. J., L. J. Lochner, and P. E. Todd (2006). Earnings equations and rates of return: The Mincer equation and beyond. In E. A. Hanushek and F. Welch (Eds.), Handbook of the Economics of Education, Chapter 7, pp. 307-458. Amsterdam: North-Holland.

Heckman, J. J. and S. Polachek (1974, June). Empirical evidence on the functional form of the earnings-schooling relationship. Journal of the American Statistical Association 69(346), 350-354.

Heckman, J. J. and R. Robb (1985). Using longitudinal data to estimate age, period and cohort effects in earnings equations. In W. M. Mason and S. E. Fienberg (Eds.), Cohort Analysis in Social Research: Beyond the Identification Problem. New York: SpringerVerlag.

Katz, L. F. and D. H. Autor (1999). Changes in the wage structure and earnings inequality. In O. Ashenfelter and D. Card (Eds.), Handbook of Labor Economics, Volume 3, Chapter 25, pp. 1463-1555. New York: North-Holland.

Ljungqvist, L. and T. J. Sargent (2004, April-May). European unemployment and turbulence revisited in a matching model. Journal of the European Economic Association 2(2-3), $456-468$. 
MaCurdy, T. E. (1982, January). The use of time series processes to model the error structure of earnings in a longitudinal data analysis. Journal of Econometrics 18(1), 83-114.

MaCurdy, T. E. (2007). A practitioner's approach to estimating intertemporal relationships using longitudinal data: Lessons from applications in wage dynamics. In J. J. Heckman and E. Leamer (Eds.), Handbook of Econometrics, Volume 6A of Handbooks in Economics, Chapter 62. Amsterdam: Elsevier. Forthcoming.

Matzkin, R. L. (1992, March). Nonparametric and distribution-free estimation of the binary threshold crossing and the binary choice models. Econometrica 60(2), 239-270.

Miller, S. (2004). The National Longitudinal Surveys NLSY79 User's Guide 1979-2002. Washington, DC: Bureau of Labor Statistics, U.S. Department of Labor.

Mincer, J. (1974). Schooling, Experience and Earnings. New York: Columbia University Press for National Bureau of Economic Research.

Navarro, S. (2007). Reconsidering the importance of borrowing constraints, uncertainty and preferences for college attendance: Using observed choices to infer agent's information. Unpublished manuscript, University of Wisconsin, Department of Economics.

Roy, A. (1951, June). Some thoughts on the distribution of earnings. Oxford Economic Papers 3(2), 135-146.

Schennach, S. M. (2004, January). Estimation of nonlinear models with measurement error. Econometrica 72(1), 33-75.

Sen, A. K. (2000). Social justice and the distribution of income. In A. B. Atkinson and F. Bourguignon (Eds.), Handbook of Income Dynamics, Volume 1, pp. 59-85. Amsterdam: North-Holland.

Sims, C. A. (1972, September). Money, income, and causality. American Economic Review 62(4), 540-552. 
Table 1:

\begin{tabular}{|c|c|c|}
\hline $\begin{array}{r}\text { Schooling Choice and } \mathrm{F} \\
\text { Compar }\end{array}$ & $\begin{array}{l}\text { tes of } \mathrm{R} \\
\text { on Acro }\end{array}$ & $\begin{array}{l}\text { Year of } \\
\text { ts }\end{array}$ \\
\hline & NLS/66 & NLSY/79 \\
\hline High School Graduates & $58.17 \%$ & $64.19 \%$ \\
\hline College Graduates & $41.83 \%$ & $35.81 \%$ \\
\hline Mincer Returns to College ${ }^{1}$ & $9.01 \%$ & $11.96 \%$ \\
\hline Mincer Returns to College ${ }^{2}$ & $10.17 \%$ & $12.41 \%$ \\
\hline Mincer Returns to College ${ }^{3}$ & $8.17 \%$ & $11.00 \%$ \\
\hline
\end{tabular}

${ }^{1}$ Pooled OLS Regression, controlling only for Mincer Experience and Mincer Experience Squared

${ }^{2}$ Pooled OLS Regression, controlling for Mincer Experience, Mincer Experience Squared, and Year Dummies

${ }^{3}$ Pooled OLS Regression, controlling for Mincer Experience, Mincer Experience Squared, Cognitive Skills, Urban and South Residence at Age 14, and Year Dummies (Dependent Variable: Log Earnings). 
Table 2:

\begin{tabular}{lcccc}
\hline \hline \multicolumn{1}{c}{ Mean Rates of Return per Year of College by Schooling Group } \\
& \multicolumn{2}{c}{ NLS/66 } & \multicolumn{2}{c}{ NLSY/79 } \\
Schooling Group & Mean Returns & Standard Error & Mean Returns & Standard Error \\
High School Graduates & 0.0592 & 0.0046 & 0.0955 & 0.0063 \\
College Graduates & 0.0877 & 0.0070 & 0.1355 & 0.0080 \\
Individuals at the Margin & 0.0750 & 0.0178 & 0.1184 & 0.0216 \\
\hline \hline
\end{tabular}




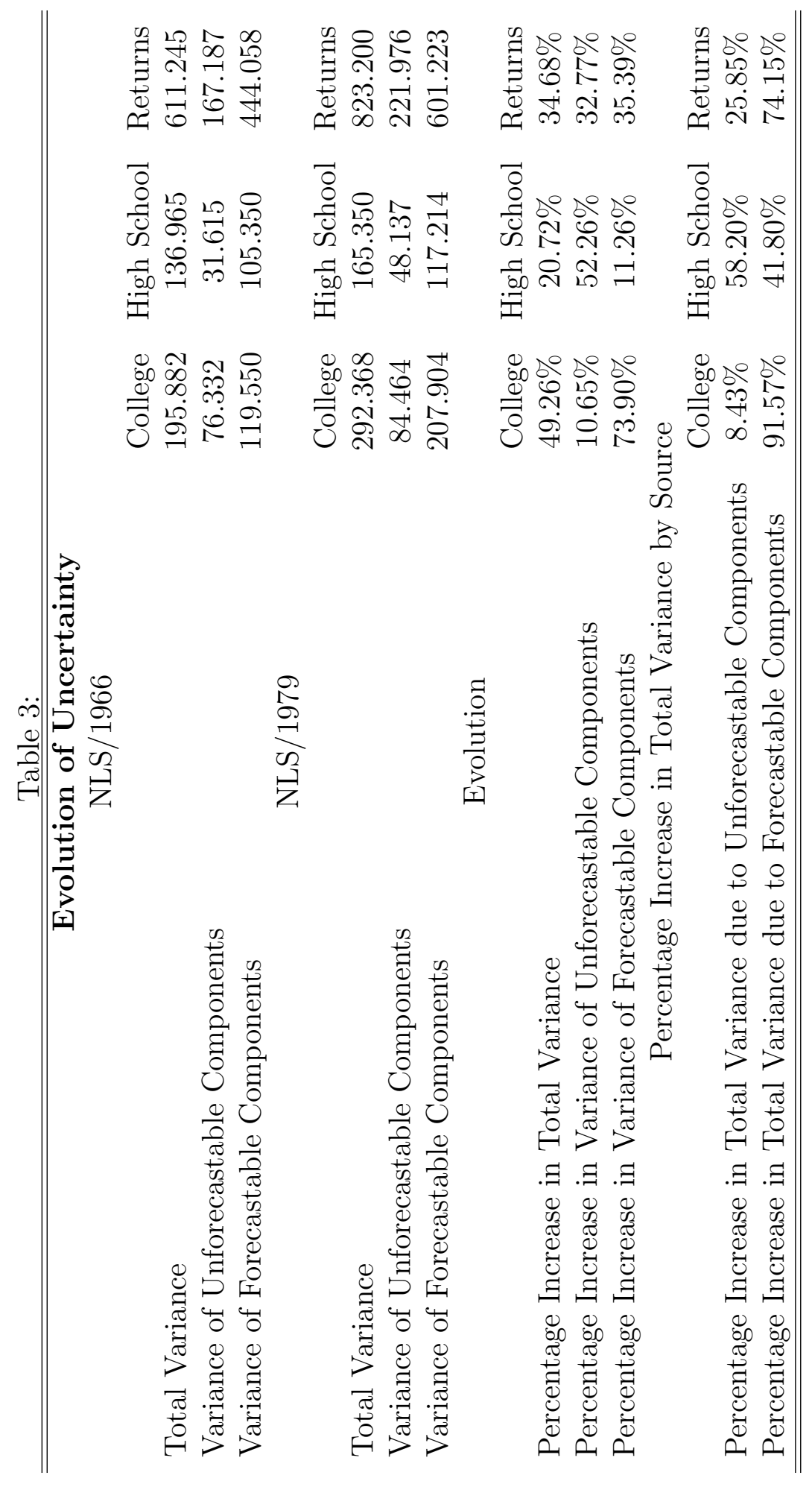


Table 4:

\begin{tabular}{lcccc}
\hline \hline & \multicolumn{3}{c}{ Share of Variance of Business Cycle } \\
& in Total Variance of Unforecastable Components & \\
& \multicolumn{2}{c}{ NLS/1966 } & \multicolumn{2}{c}{ NLSY / 1979} \\
High School & 0.1111 & 0.0147 & 0.0156 & 0.0020 \\
College & 0.0452 & 0.0077 & 0.0392 & 0.0052 \\
Overall & 0.0679 & 0.0107 & 0.0328 & 0.0042 \\
\hline \hline
\end{tabular}




\section{A}

\section{Gini Decomposition}

Factual Economy: Heterogeneity and Uncertainty ${ }^{1}$ Counterfactual: Fixing Schooling Choices as in Factual Economy Heterogeneity Only ${ }^{2}$

$\begin{array}{ccc}\text { NLS /66 } & \text { NLSY/79 } & \text { \%Growth } \\ 0.1803 & 0.2088 & 15.85 \% \\ & & \\ 0.1591 & 0.1825 & 14.73 \%\end{array}$

NLS/66 NLSY/79 \%Growth

$0.1591 \quad 0.1825 \quad 14.73 \%$

\section{B}

The Theil Entropy Index T

Overall

Factual Economy: Heterogeneity and Uncertainty ${ }^{1}$

NLS/66 NLSY/79 \%Growth

Counterfactual: Fixing Schooling Choices as in Factual Economy

Heterogeneity Only ${ }^{2}$

\section{Within Schooling Groups}

Factual Economy: Heterogeneity and Uncertainty ${ }^{1}$

0.0693

$37.98 \%$

$0.0390 \quad 0.0522 \quad 33.76 \%$

Counterfactual: Fixing Schooling Choices as in Factual Economy

Heterogeneity Only ${ }^{2}$

\section{Between Schooling Groups}

Factual Economy: Heterogeneity and Uncertainty ${ }^{1}$

NLS/66 NLSY/79 \%Change

$0.0491 \quad 0.0631 \quad 28.53 \%$

$0.0378 \quad 0.0465 \quad 22.85 \%$

NLS/66 NLSY/79 \%Change

$0.0011 \quad 0.0062 \quad 447.37 \%$

Counterfactual: Fixing Schooling Choices as in Factual Economy Heterogeneity Only ${ }^{2}$

\begin{tabular}{lll}
$0.0011 \quad 0.0057 \quad 394.22 \%$ \\
\hline
\end{tabular}

$\overline{\overline{1} \text { Let } Y_{k, s, t, i} \text { denote the earnings of an agent } i, i=1, \ldots, n_{k}, \text { at age } t, t=22, \ldots, 36, \text { in schooling level } s}$, $s=$ high school, college, and cohort $k, k=N L S / 1966, N L S Y / 1979$. We model earnings $Y_{k, s, t, i}$ as:

$$
Y_{k, s, t, i}=\mu_{s, k}\left(X_{k}\right)+\theta_{1, k, i} \alpha_{1, k, s, t, i}+\theta_{2, k, i} \alpha_{2, k, s, t, i}+\theta_{3, k, i} \alpha_{3, k, s, t, i}+\varepsilon_{k, s, t, i} .
$$

The present value of earnings at schooling level $s, Y_{k, s, i}$, is $Y_{k, s, i}=\sum_{t=1}^{T^{*}} \frac{Y_{k, s, t, i}}{(1+\rho)^{t-1}}$. The observed present value of earnings satisfies $Y_{k, i}=S_{k, i} Y_{k, 1, i}+\left(1-S_{k, i}\right) Y_{k, 0, i}$ where $S_{k, i}=1$ if agent $i$ in cohort $k$ graduates college, and $S_{k, i}=0$ if the person graduates high school. Let $C_{k, i}$ denote the direct costs for individual $i$ in cohort $k$. The schooling choice is:

$$
S_{k, i}=1 \Leftrightarrow E\left(Y_{k, 1, i}-Y_{k, 0, i}-C_{k, i} \mid \mathcal{I}_{k}\right) \geq 0 .
$$

This is the factual economy. In this row, we show the inequality measure in the subtitle.

${ }^{2}$ We simulate the economy by replacing (i) with:

$$
Y_{k, s, t, i}^{h}=\mu_{s, k}\left(X_{k}\right)+\theta_{1, k, i} \alpha_{1, k, s, t, i}+\theta_{2, k, i} \alpha_{2, k, s, t, i}
$$

where $Y_{k, s, t, i}^{h}$ are the individual earnings when idiosyncratic uncertainty is completely shut down. The present value of earnings when only heterogeneity is accounted for is constructed in a similar manner: $Y_{k, s, i}^{h}=\sum_{t=1}^{T^{*}} \frac{Y_{k, s, t, i}^{h}}{(1+\rho)^{t-1}}$. The schooling choices are as determined in (ii). In this row, we show the inequality measure for the concept given in the subtitle for the observed truncated present value of earnings $Y_{k, s, i}^{h}$ when we constrain schooling choices to be the same as in the economy that generates the first row. 


\section{Atkinson Index}

Factual Economy: Heterogeneity and Uncertainty ${ }^{1}$ Counterfactual: Fixing Schooling Choices as in Factual Economy Heterogeneity Only ${ }^{2}$

Factual Economy: Heterogeneity and Uncertainty ${ }^{1}$ Counterfactual: Fixing Schooling Choices as in Factual Economy Heterogeneity Only ${ }^{2}$

\section{NLS $/ 66$ \\ $\mathrm{NLS} / 66$
0.0276}

0.0213

\section{$\varepsilon=0.5$ \\ NLSY $/ 79$}

0.0389

0.0286

0.4111

NLS/66

$$
\varepsilon=1.0
$$

NLSY $/ 79$ \%Change

$0.0847 \quad 0.4446$

$\varepsilon=1.5$

0.3437

0.0447

0.0604

0.3503

\begin{tabular}{cccccc} 
& $\varepsilon=1.5$ & & \multicolumn{3}{c}{$\varepsilon=2.0$} \\
NLS/66 & NLSY $/ 79$ & \%Change & NLS/66 & NLSY $/ 79$ & \%Change \\
0.0968 & 0.1467 & 0.5147 & 0.1627 & 0.2627 & 0.6149
\end{tabular}

$\begin{array}{llllll}0.0716 & 0.0980 & 0.3687 & 0.1060 & 0.1506 & 0.4205\end{array}$

$\overline{\overline{1}}$ Let $Y_{k, s, t, i}$ denote the earnings of an agent $i, i=1, \ldots, n_{k}$, at age $t, t=1, \ldots, T$, in schooling level $s, s=$ high school, college, and cohort $k, k=N L S / 1966, N L S Y / 1979$. We model earnings $Y_{k, s, t, i}$ as:

$$
Y_{k, s, t, i}=\mu_{s, k}\left(X_{k}\right)+\theta_{1, k, i} \alpha_{1, k, s, t, i}+\theta_{2, k, i} \alpha_{2, k, s, t, i}+\theta_{3, k, i} \alpha_{3, k, s, t, i}+\varepsilon_{k, s, t, i}
$$

The present value of earnings in schooling level $s, Y_{k, s, i}$, is $Y_{k, s, i}=\sum_{t=1}^{T^{*}} \frac{Y_{k, s, t, i}}{(1+\rho)^{t-1}}$. The observed truncated present value of earnings is $Y_{k, i}=S_{k, i} Y_{k, 1, i}+\left(1-S_{k, i}\right) Y_{k, 0, i}$. Let $C_{k, i}$ denote the direct costs for individual $i$ in cohort $k$. The schooling choice is:

$$
S_{k, i}=1 \Leftrightarrow E\left(Y_{k, 1, i}-Y_{k, 0, i}-C_{k, i} \mid \mathcal{I}_{k}\right) \geq 0
$$

This is the factual economy. We then compute the average present value of earnings across all individuals in cohort $k, \mu_{k}=\frac{1}{n} \sum_{i=1}^{n_{k}} Y_{k, i}$. For a given inequality aversion parameter $\epsilon$, we compute the level of permanent income $\bar{Y}_{k}(\epsilon)$ that generates the same welfare as the social welfare of the actual distribution in cohort $k$ :

$$
\frac{\left[\bar{Y}_{k}(\epsilon)\right]^{1-\epsilon}-1}{1-\epsilon}=\frac{1}{n_{k}} \sum_{i=1}^{n_{k}} \frac{\left(Y_{k, i}\right)^{1-\epsilon}-1}{1-\epsilon}
$$

For each value of $\epsilon$, the Atkinson Index is $A(\epsilon)=1-\frac{\bar{Y}_{k}(\epsilon)}{\mu_{k}}$. In this row, we show the Atkinson Index for the observed present value of earnings $Y_{k, i}$ for different values of $\epsilon$.

${ }^{2}$ We simulate the economy by replacing (i) with:

$$
Y_{k, s, t, i}^{h}=\mu_{s, k}\left(X_{k}\right)+\theta_{1, k, i} \alpha_{1, k, s, t, i}+\theta_{2, k, i} \alpha_{2, k, s, t, i}
$$

where $Y_{k, s, t, i}^{h}$ are the individual earnings when idiosyncratic uncertainty is completely shut down. The present value of earnings when only heterogeneity is accounted for is constructed in a similar manner: $Y_{k, s, i}^{h}=\sum_{t=1}^{T^{*}} \frac{Y_{k, s, t, i}^{h}}{(1+\rho)^{t-1}}$. The schooling choices are as determined in (ii). In this row, we show the Atkinson Index for the observed present value of earnings $Y_{k, i}^{h}$ for different values of $\epsilon$ when we constrain schooling choices, $S_{k, i}$, to be observed in the factual economy. 
Figure 1

Mean Earnings Profile

NLS/66 Sample

Comparison Across Schooling Within Cohorts

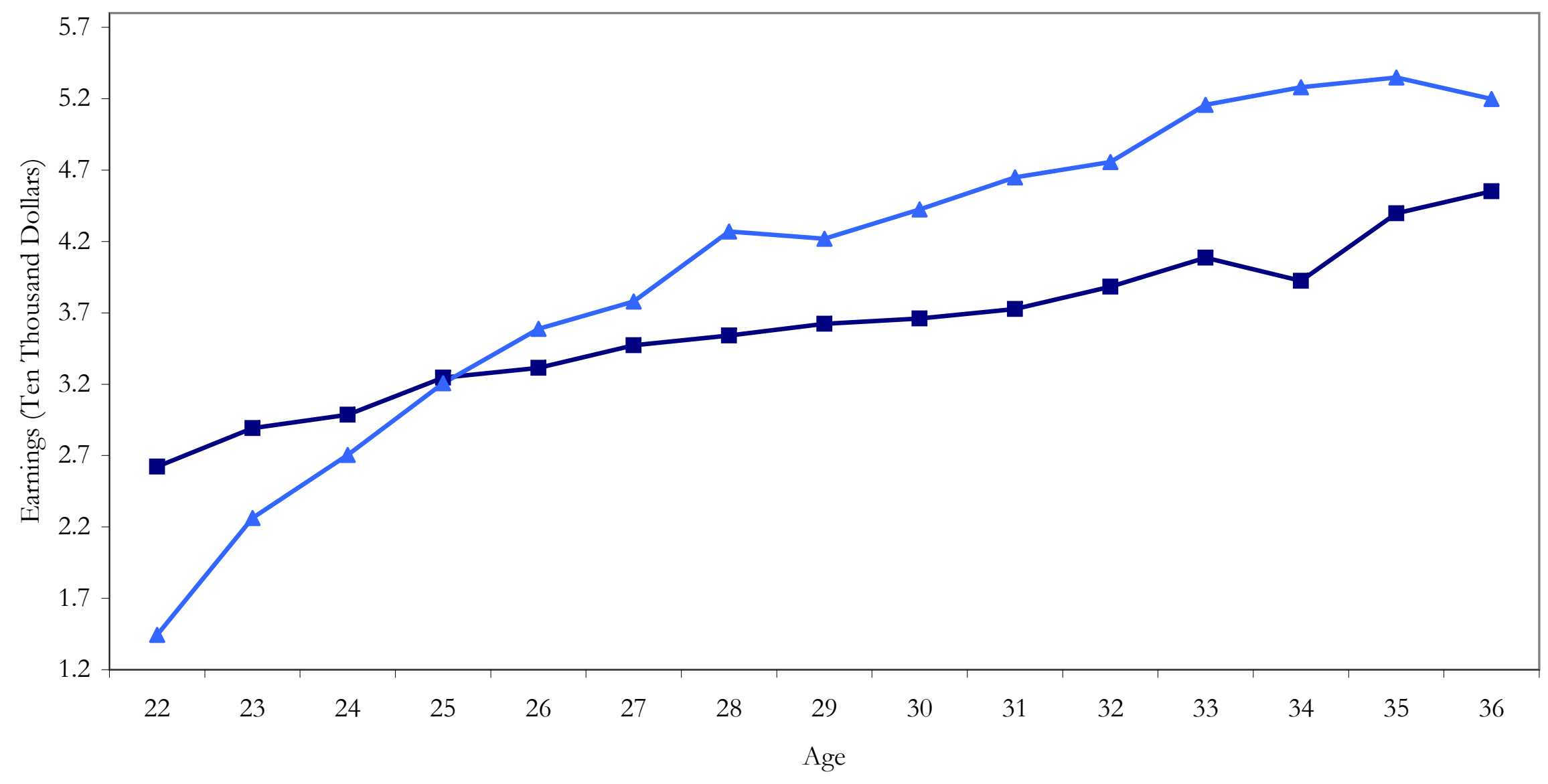

$\rightarrow$ High School - NLS/66 $\rightarrow$ College - NLS/66 
Figure 2

Mean Earnings Profile

NLSY/79 Sample

Comparison Across Schooling Within Cohorts

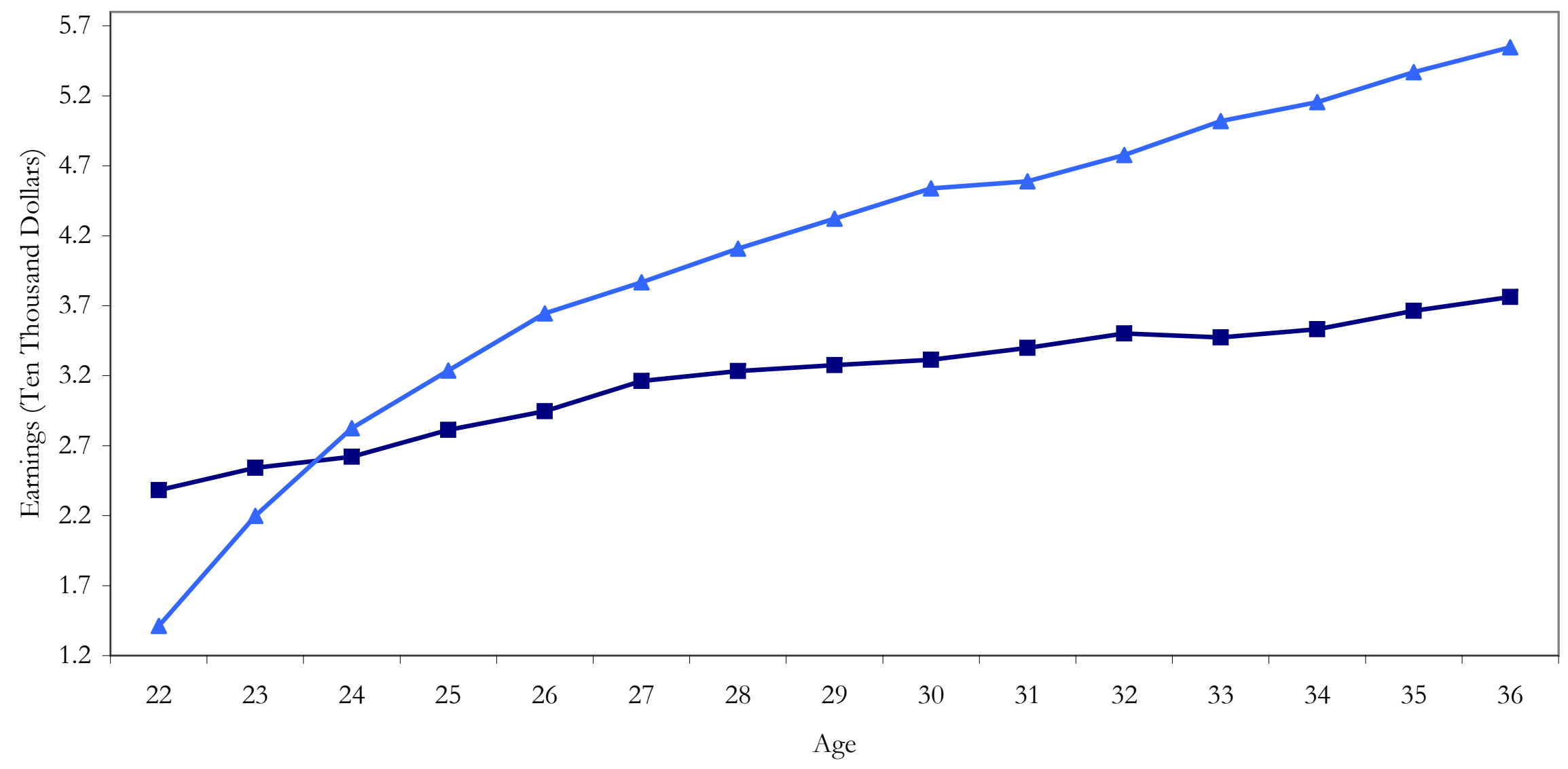

$\rightarrow$ High School - NLSY/79 $\rightarrow$ College - NLSY/79 
Figure 3

Standard Deviation of Earnings

High School Sample

Comparison Within Schooling Groups Across Cohorts

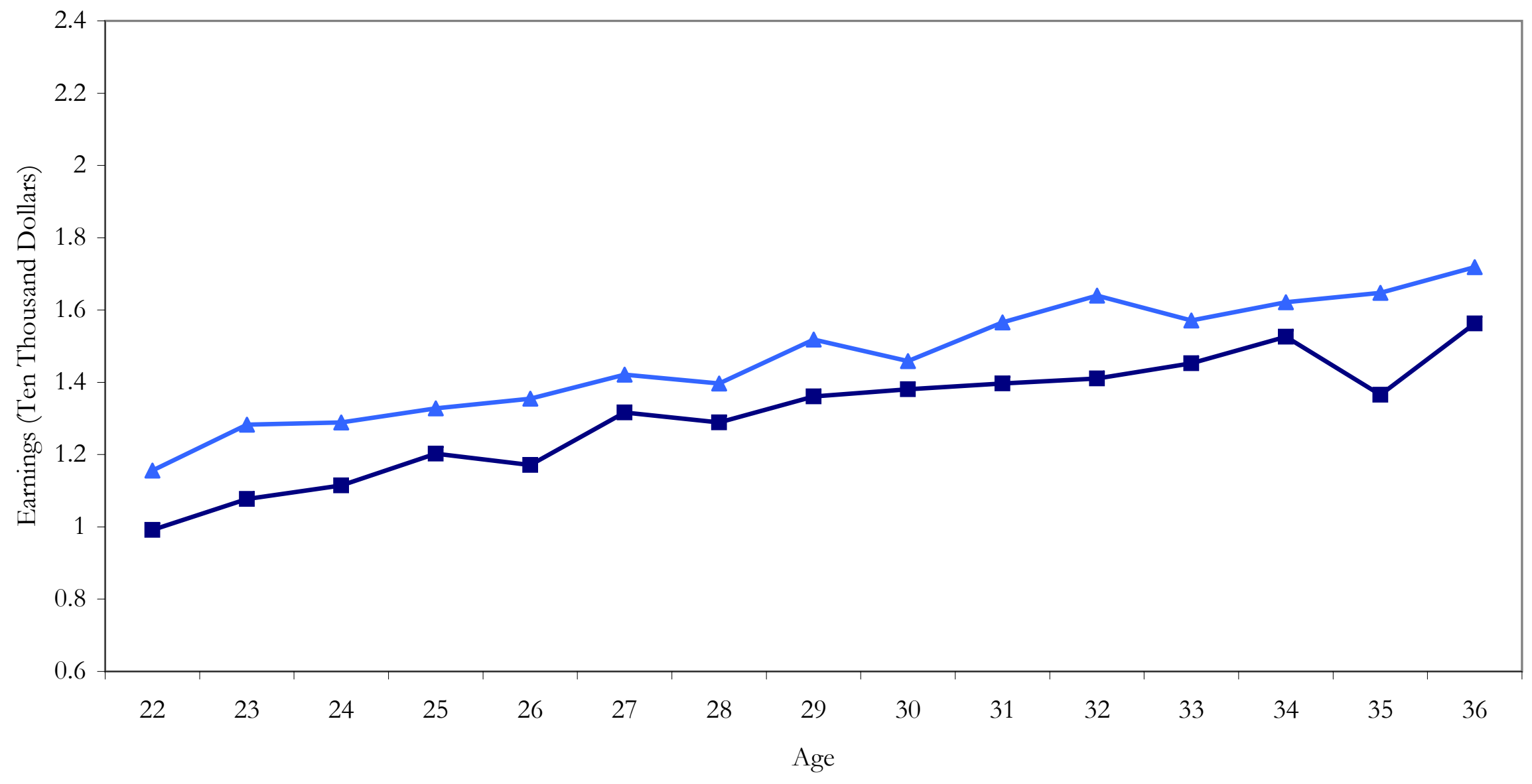

$\rightarrow$ High School - NLS/66 $\leftarrow$ High School - NLSY/79 
Figure 4

Standard Deviation of Earnings

College Sample

Comparison Within Schooling Groups Across Cohorts

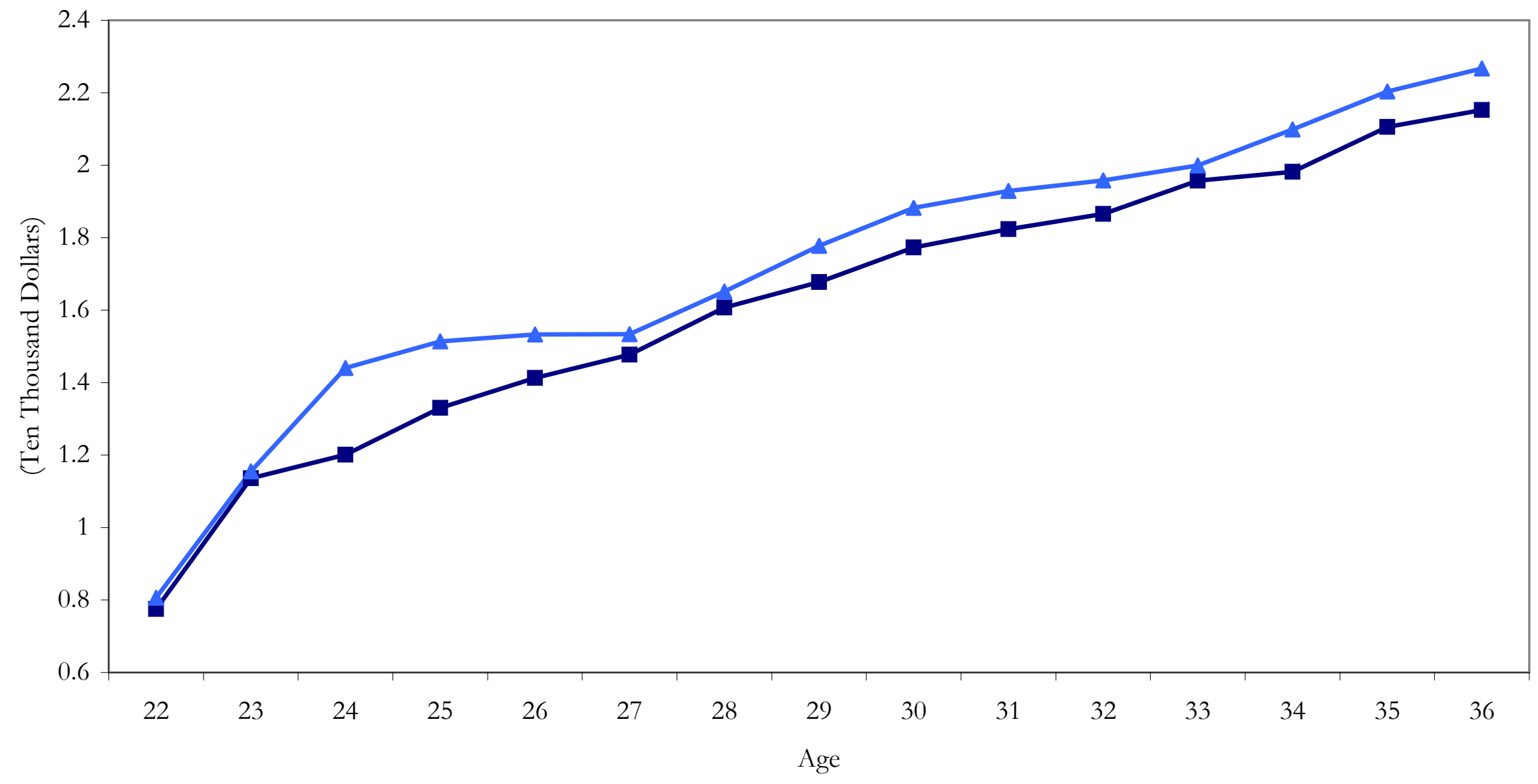

$\rightarrow$ College - NLS/66 -College - NLSY/79 
Figure 5

Densities of earnings at age 33

Overall Sample NLSY/79

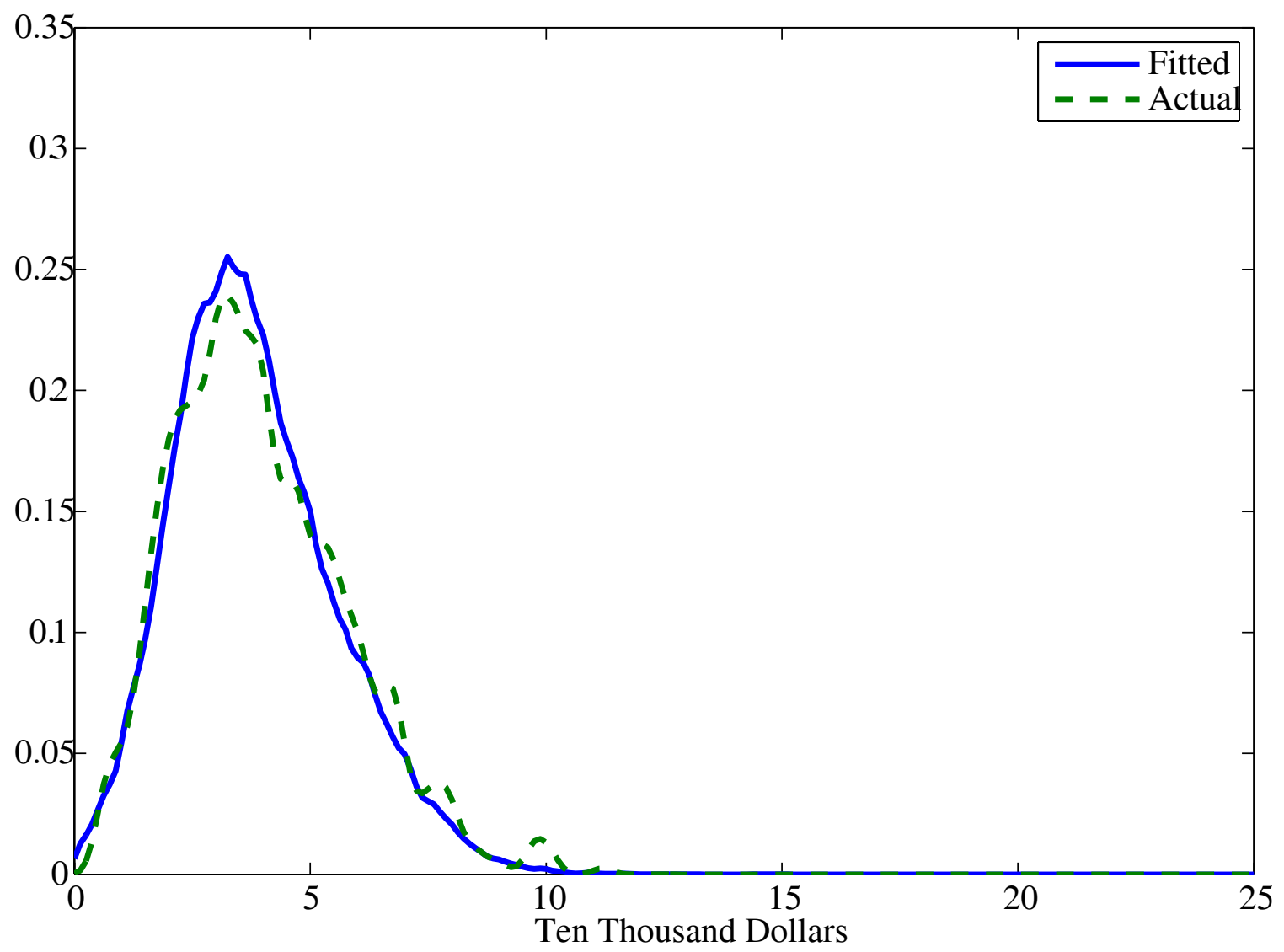

Let $\mathrm{Y}$ denote earnings at age 33 in the overall sample. Here we plot the density functions $\mathrm{f}(\mathrm{y})$ generated from the data (the solid curve), against that predicted by the model (the dashed line). 
Figure 6A

Densities of present value of earnings

High School Sample NLSY/79

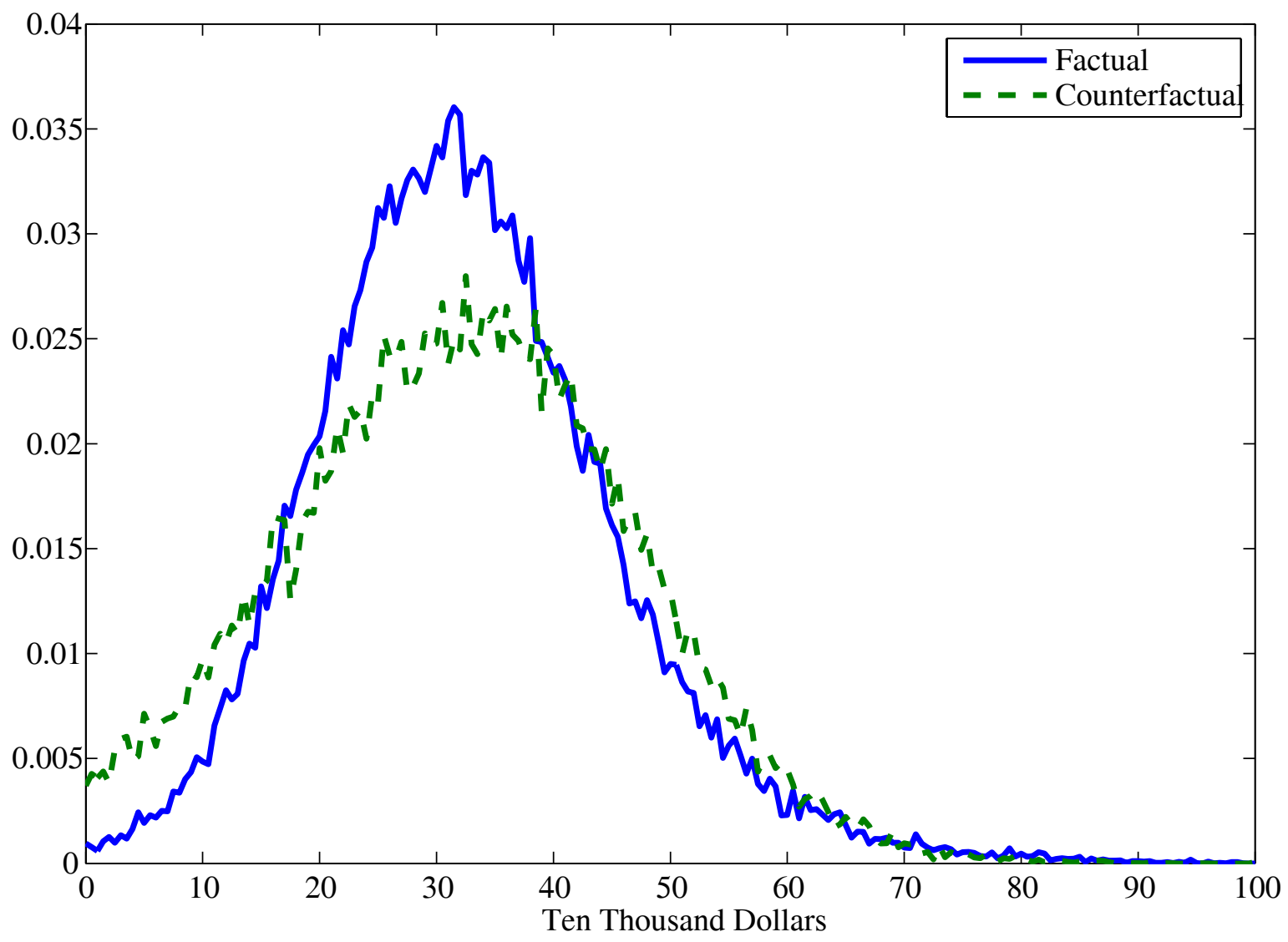

Present value of earnings from age 22 to 36 for High School Graduates discounted using an interest rate of $5 \%$. Here we plot the factual density function $\mathrm{f}\left(\mathrm{y}_{0} \mid \mathrm{S}=0\right)$ (the solid curve), against the counterfactual density function $\mathrm{f}\left(\mathrm{y}_{1} \mid \mathrm{S}=0\right)$ (the dashed.line). We use kernel density estimation to smooth these functions. 
Figure 6B

Densities of present value of earnings

High School Sample NLS/1966

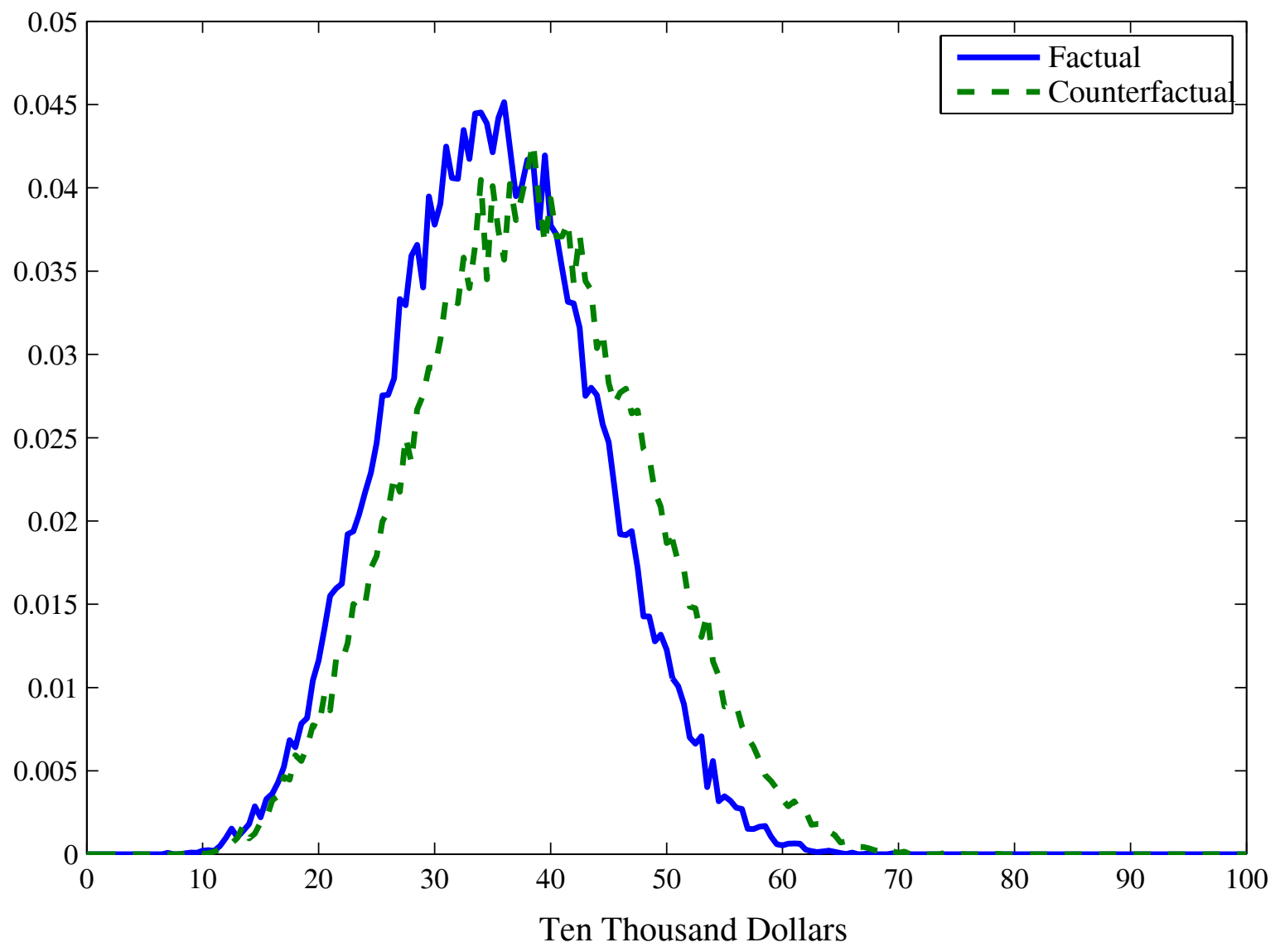

Present value of earnings from age 22 to 36 for High School Graduates discounted using an interest rate of $5 \%$. Here we plot the factual density function $\mathrm{f}\left(\mathrm{y}_{0} \mid \mathrm{S}=0\right)$ (the solid curve), against the counterfactual density function $\mathrm{f}\left(\mathrm{y}_{1} \mid \mathrm{S}=0\right)$ (the dashed line). We use kernel density estimation to smooth these functions. 
Figure 7A

Densities of present value of earnings to age 36

College Sample NLSY/79

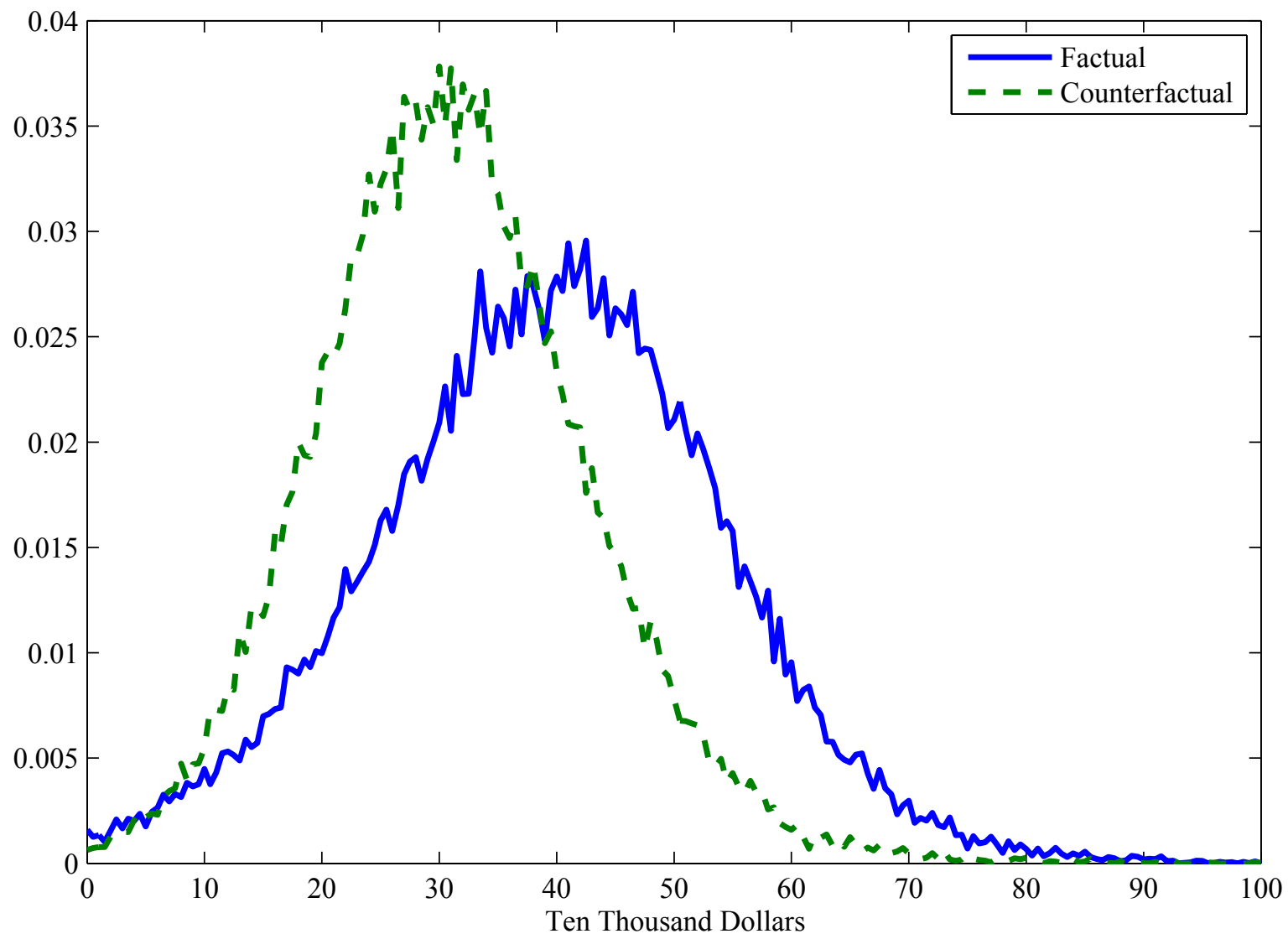

Present value of earnings from age 22 to 36 for College Graduates discounted using an interest rate of $5 \%$. Here we plot the factual density function $\mathrm{f}\left(\mathrm{y}_{1} \mid \mathrm{S}=1\right)$ (the solid curve), against the counterfactual density function $\mathrm{f}\left(\mathrm{y}_{0} \mid \mathrm{S}=1\right)$ (the dashed line). We use kernel density estimation to smooth these functions. 
Figure 7B

Densities of present value of earnings to age 36

College Sample NLS/1966

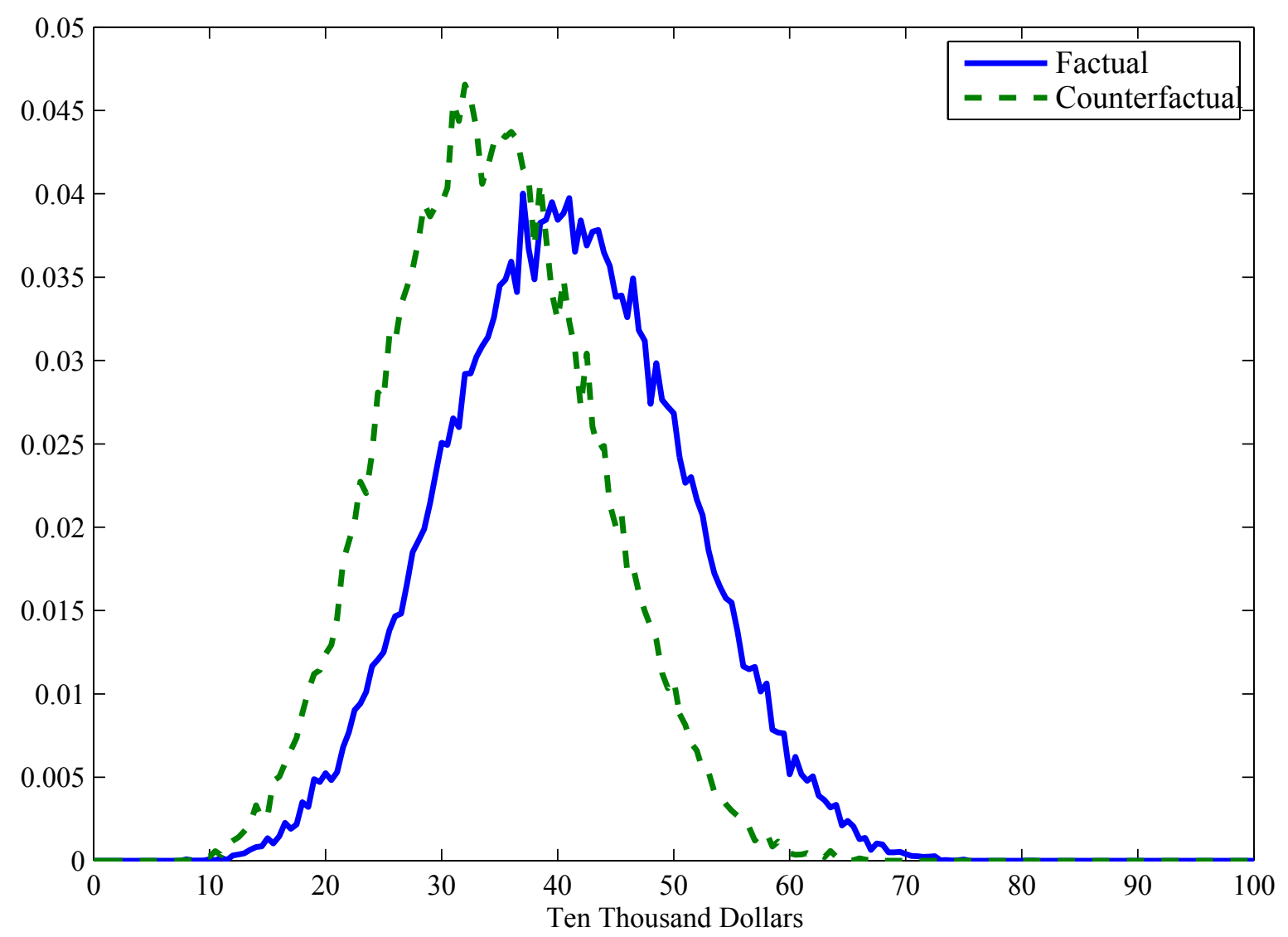

Present value of earnings from age 22 to 36 for College Graduates discounted using an interest rate of $5 \%$. Here we plot the factual density function $\mathrm{f}\left(\mathrm{y}_{1} \mid \mathrm{S}=1\right)$ (the solid curve), against the counterfactual density function $\mathrm{f}\left(\mathrm{y}_{0} \mid \mathrm{S}=1\right)$ (the dashed line). We use kernel density estimation to smooth these functions. 
Figure 8A

\section{Densities of Gross Returns to College NLSY/79 Sample}

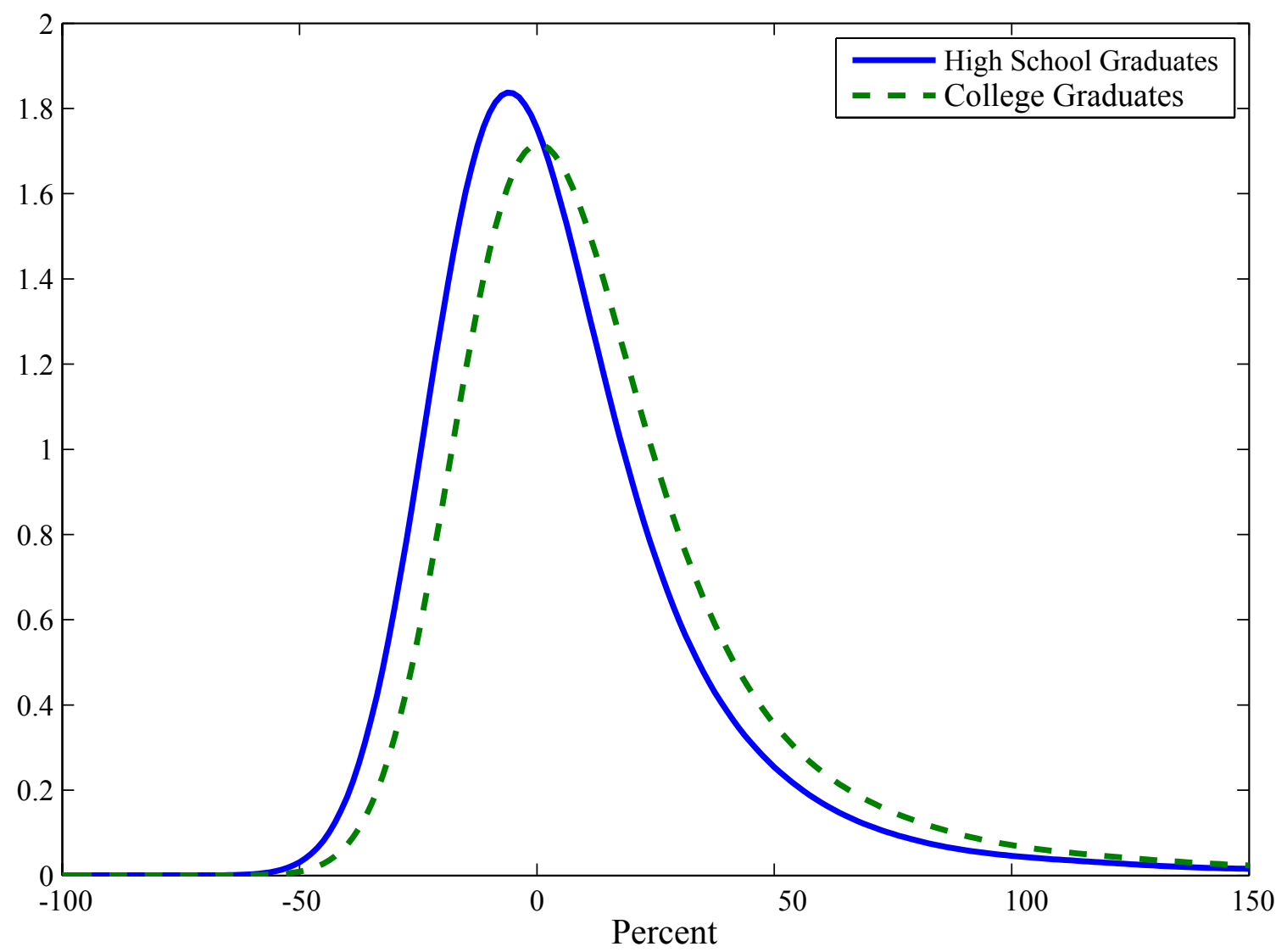

Let $\mathrm{Y}_{0}, \mathrm{Y}_{1}$ denote the present value of earnings from age 22 to age 36 in the high school and college sectors, respectively. Define ex post returns to college as the ratio $R=\left(Y_{1}-Y_{0}\right) / Y_{0}$. Let $\mathrm{f}(\mathrm{r})$ denote the density function of the random variable $\mathrm{R}$. The solid line is the density of ex post returns to colege for high school graduates, that is $\mathrm{f}(\mathrm{r} \mid \mathrm{S}=0)$. The dashed line is the density of ex post returns to college for college graduates, that is, $f(r \mid S=1)$. This assumes that the agent chooses schooling without knowing $\mathrm{q}_{3}$ and the innovations $\mathrm{e}_{\mathrm{s}, \mathrm{t}}$ for $\mathrm{s}=$ high school, college and $\mathrm{t}=22, \ldots, 36$. 
Figure 8B

Densities of Gross Returns to College

NLS/1966 Sample

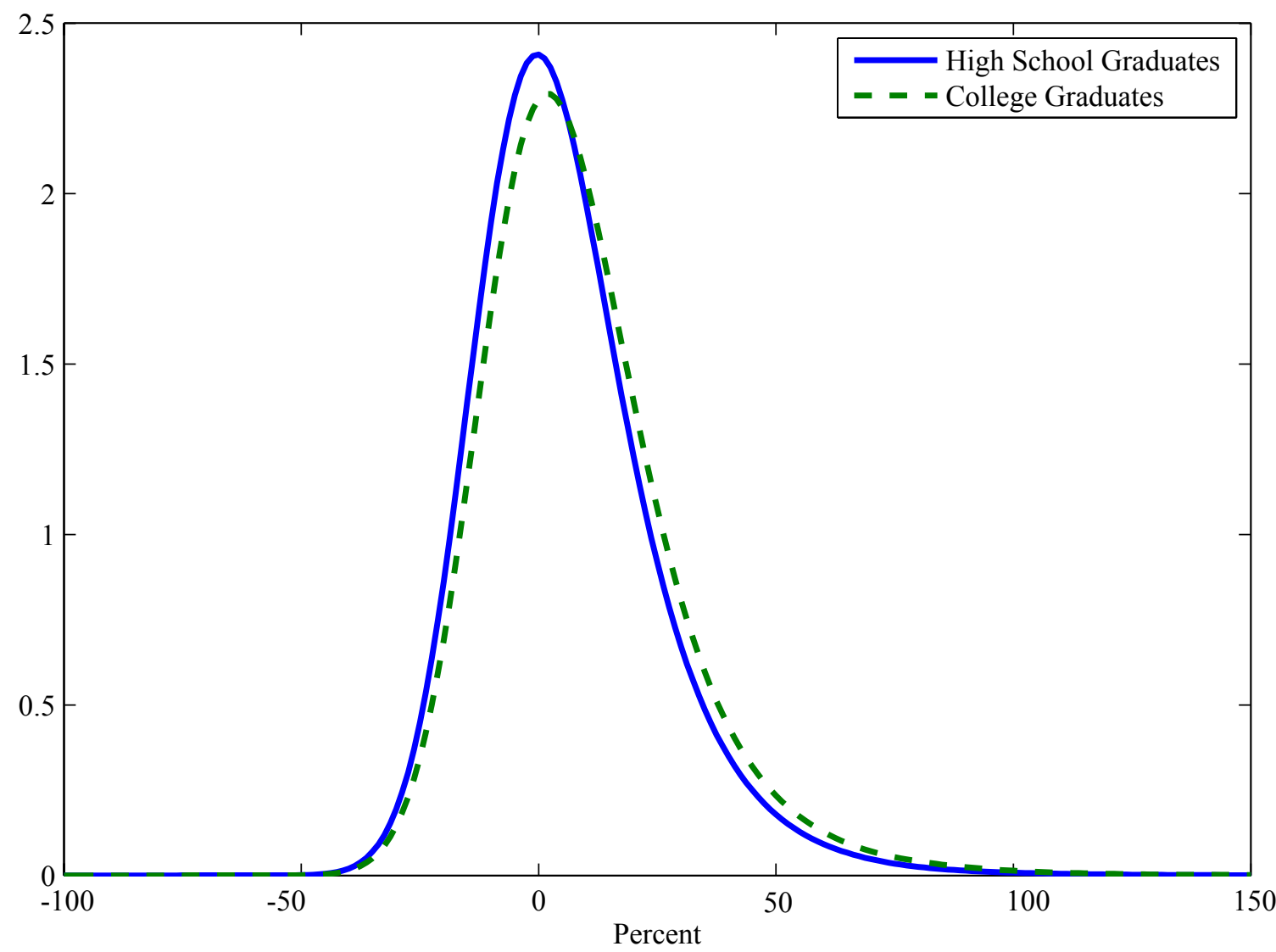

Let $\mathrm{Y}_{0}, \mathrm{Y}_{1}$ denote the present value of earnings from age 22 to age 36 in the high school and college sectors, respectively. Define ex post returns to college as the ratio $R=\left(Y_{1}-Y_{0}\right) / Y_{0}$. Let $\mathrm{f}(\mathrm{r})$ denote the density function of the random variable $\mathrm{R}$. The solid line is the density of ex post returns to colege for high school graduates, that is $\mathrm{f}(\mathrm{r} \mid \mathrm{S}=0)$. The dashed line is the density of ex post returns to college for college graduates, that is, $\mathrm{f}(\mathrm{r} \mid \mathrm{S}=1)$. This assumes that the agent chooses schooling without knowing $\mathrm{q}_{3}$ and the innovations $\mathrm{e}_{\mathrm{s}, \mathrm{t}}$ for $\mathrm{s}=$ high school, college and $\mathrm{t}=22, \ldots, 36$. 
Figure 9A

The densities of total and unforecastable components in present value of high school earnings for the NLSY/79 sample

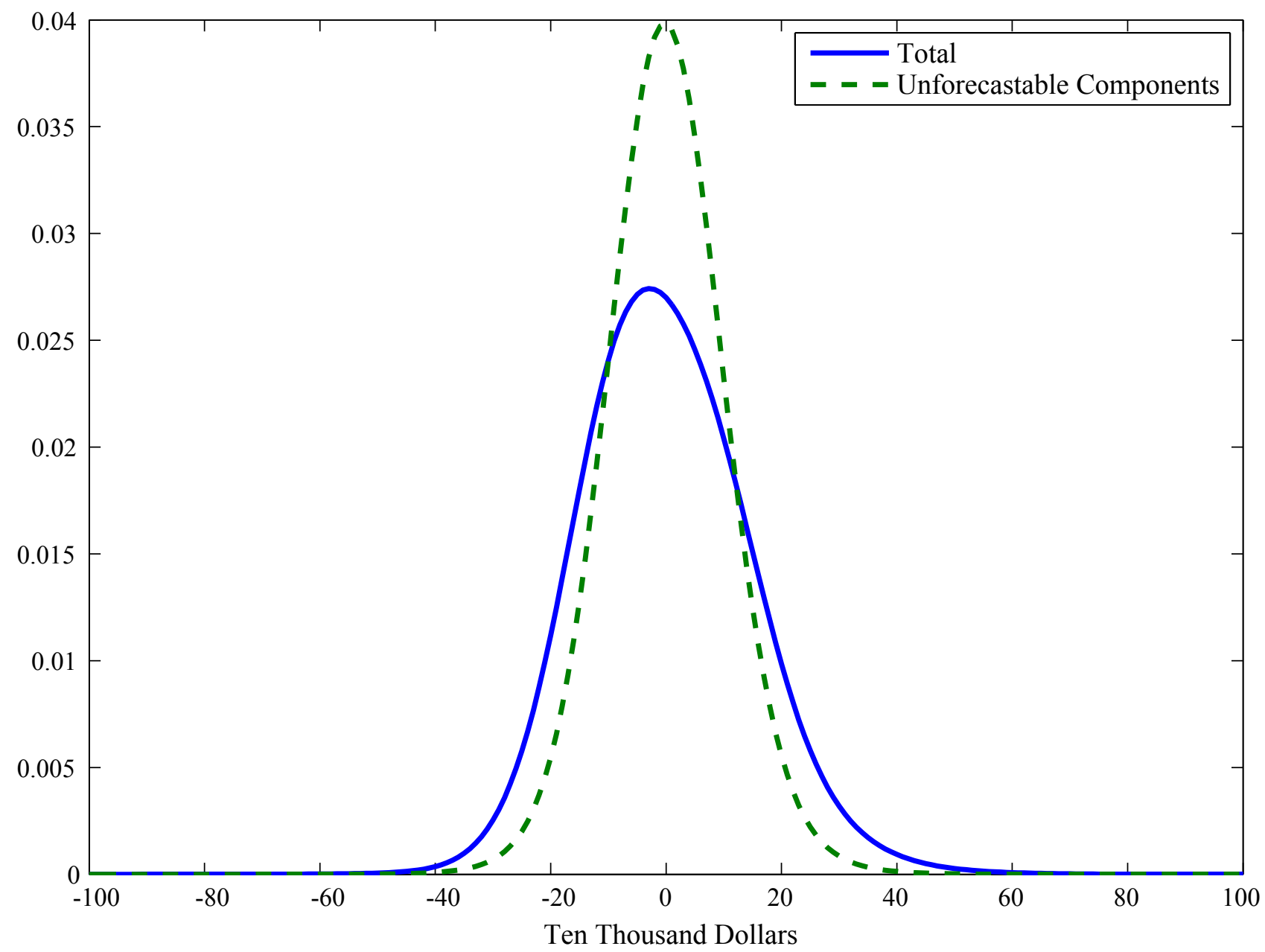

In this figure we plot the density of total (the solid curve) against the density of the unforecastable components (the dashed curve) for the present value of high-school earnings from ages 22 to 36 for the NLSY/79 sample of white males. The present value of earnings is calculated using a $5 \%$ interest rate. 
Figure 9B

The densities of total and unforecastable components in present value of high school earnings for the NLS/66 sample

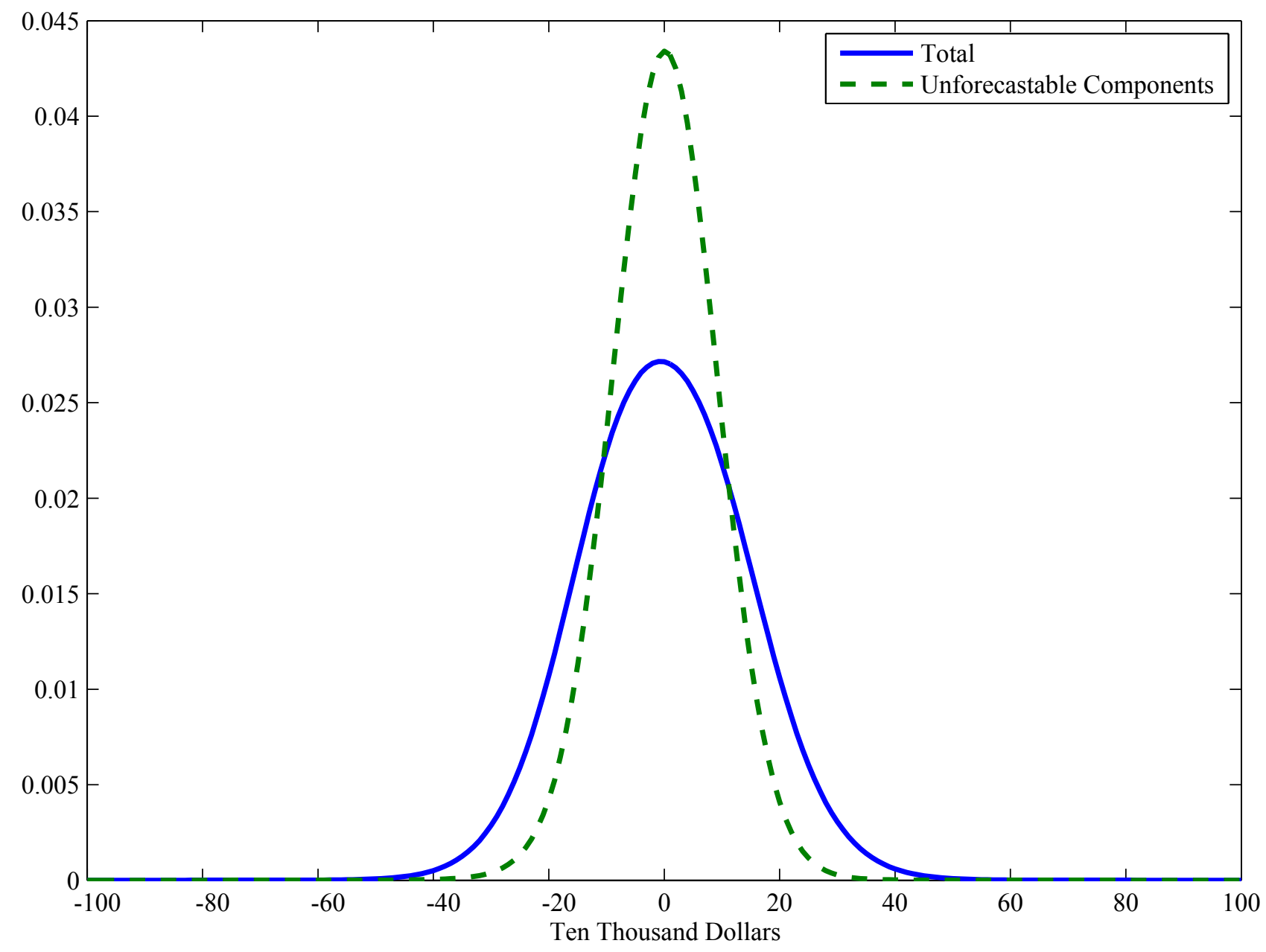

In this figure we plot the density of total (the solid curve) against the density of the unforecastable components (the dashed curve) for the present value of high-school earnings from ages 22 to 36 for the NLS/66 sample of white males. The present value of earnings is calculated using a $5 \%$ interest rate. 
Figure 10A

The densities of total and unforecastable components in present value of college earnings for the NLSY/79 sample

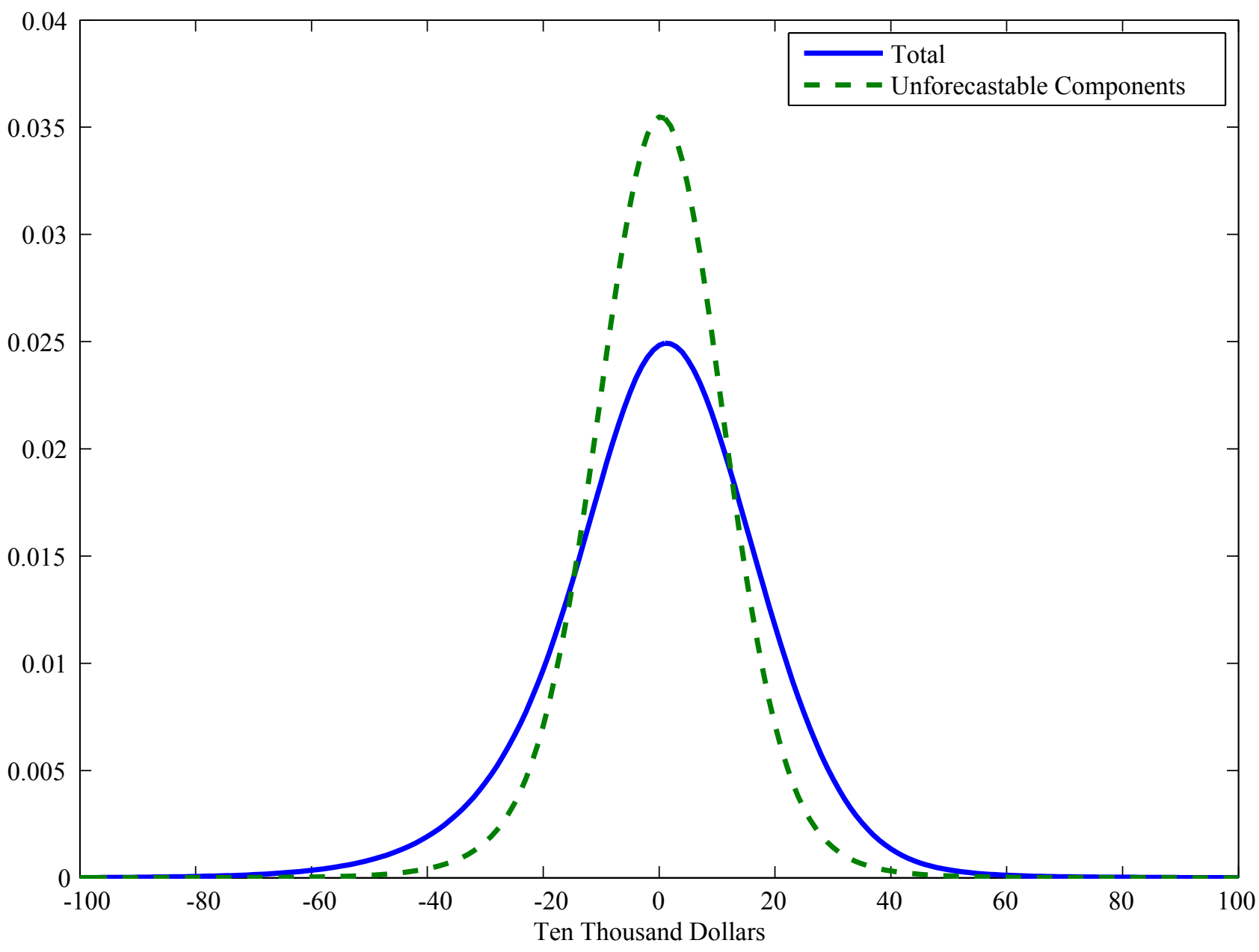

In this figure we plot the density of total (the solid curve) against the density of the unforecastable components (the dashed curve) for the present value of college earnings from ages 22 to 36 for the NLSY/79 sample of white males. The present value of earnings is calculated using a $5 \%$ interest rate. 
Figure 10B

The densities of total and unforecastable components in present value of college earnings for the NLS/66 sample

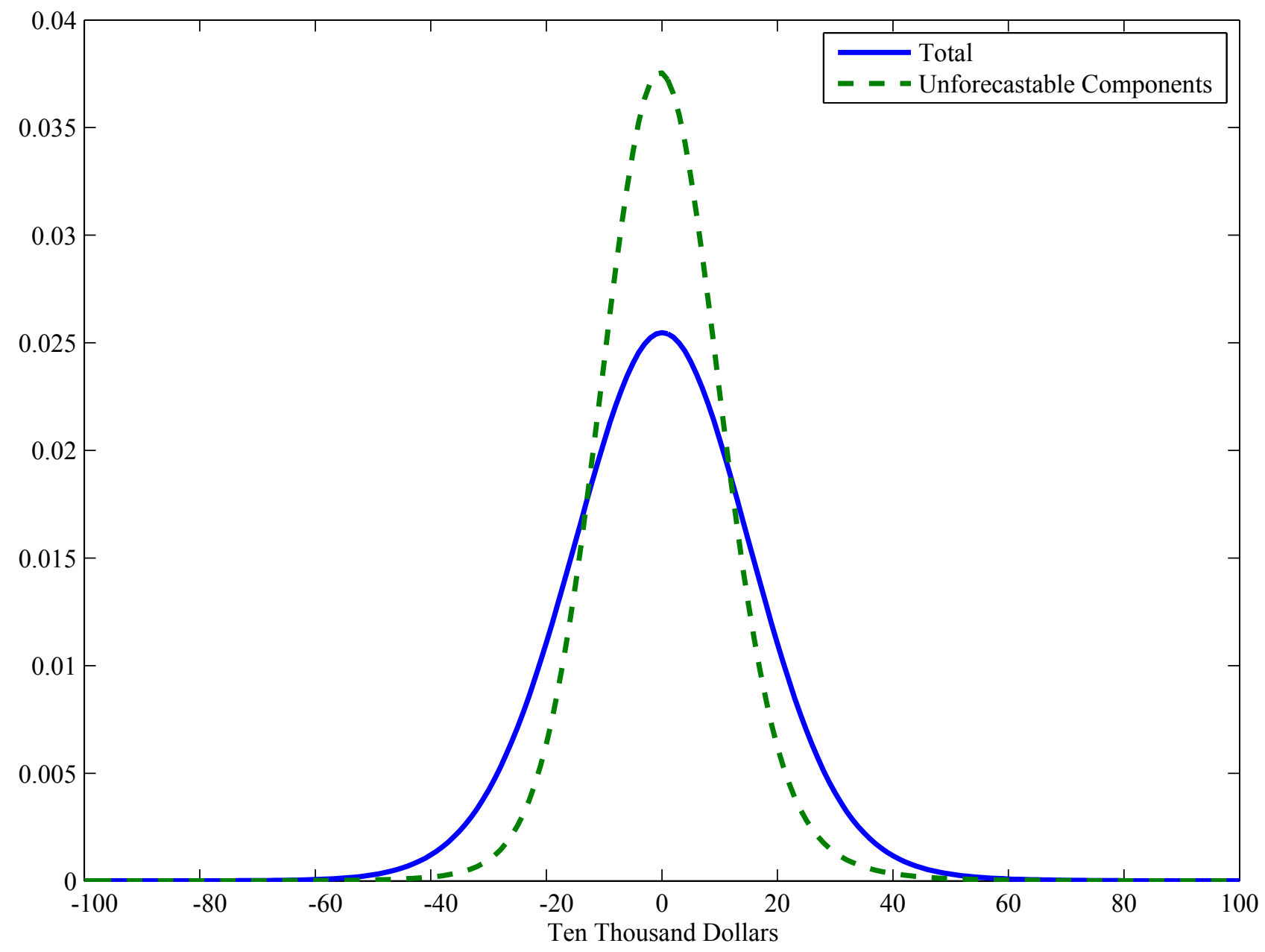

In this figure we plot the density of total (the solid curve) against the density of the unforecastable components (the dashed curve) for the present value of college earnings from ages 22 to 36 for the NLS/66 sample of white males. The present value of earnings is calculated using a $5 \%$ interest rate. 
Figure 11A

The densities of total and unforecastable components for the gross returns college vs high school for the NLS/66 Sample

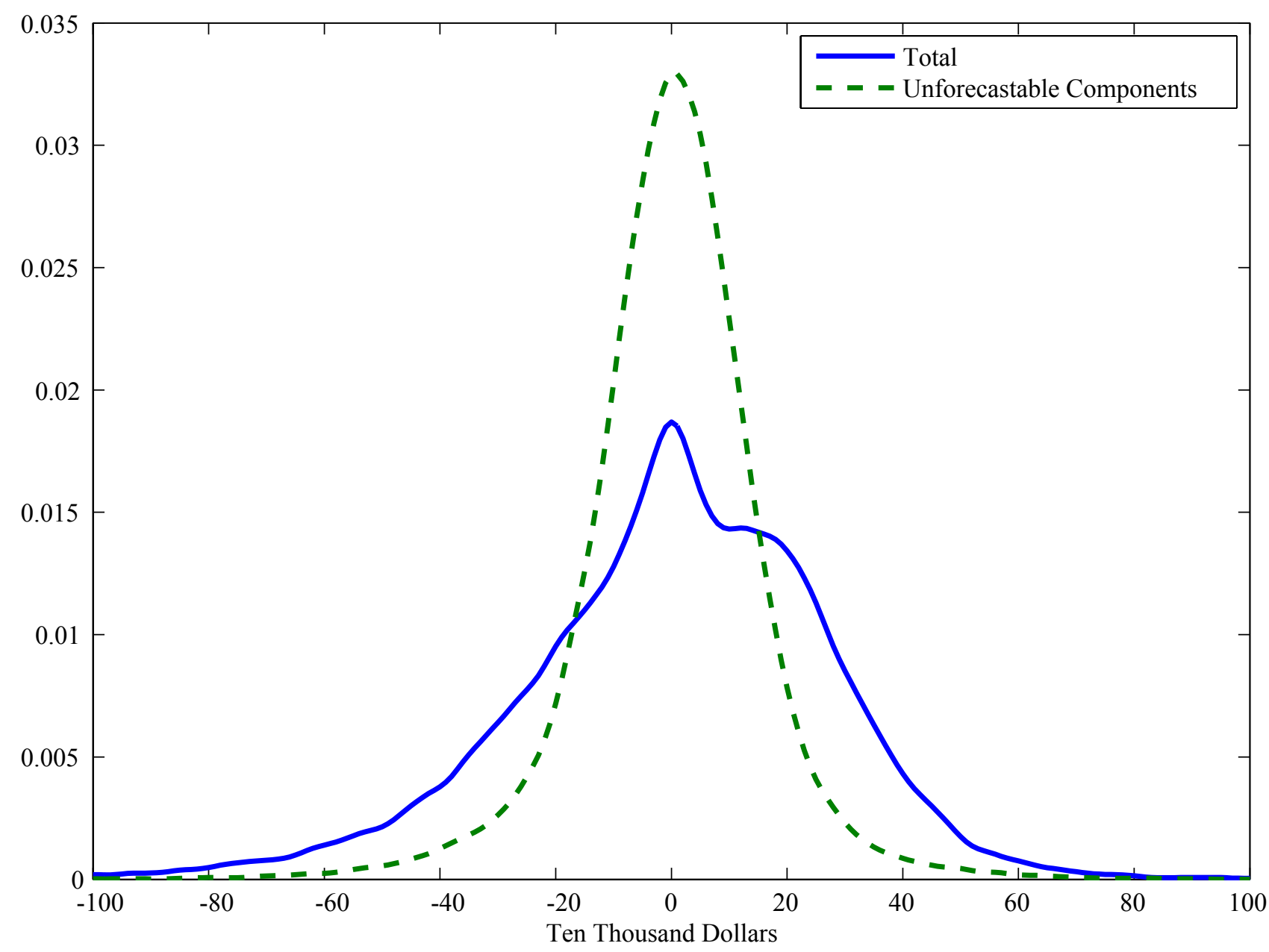

In this figure we plot the density of total (the solid curve) against the density of the unforecastable components (the dashed curve) for the present value of earnings differences (or returns to college) from ages 22 to 36 for the NLSY/79 sample of white males. The present value of earnings is calculated using a $5 \%$ interest rate. 
Figure 11B

The densities of total and unforecastable components for the gross returns college vs high school for the NLS/66 Sample

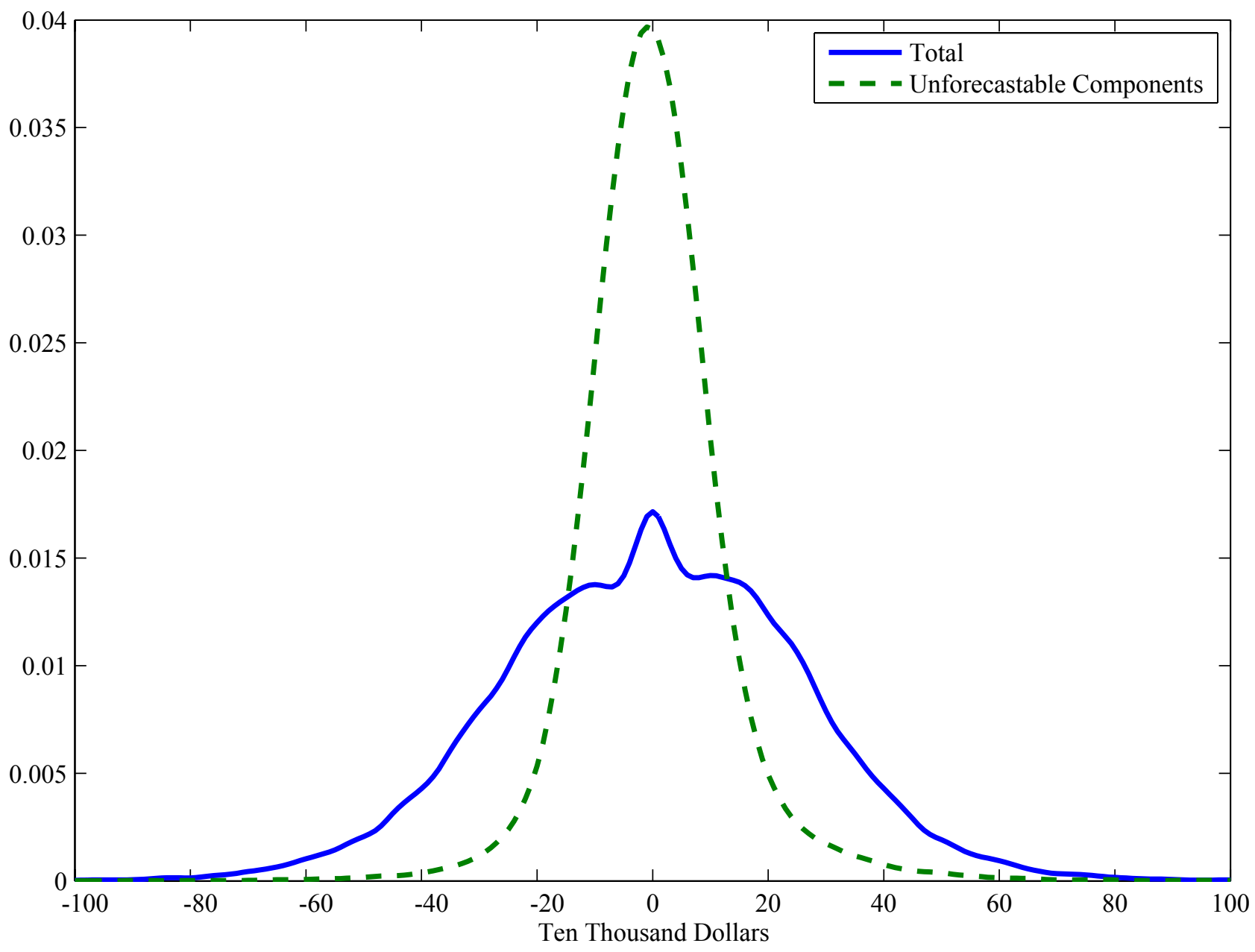

In this figure we plot the density of total (the solid curve) against the density of the unforecastable components (the dashed curve) for the present value of earnings differences (or returns to college) from ages 22 to 36 for the NLS/66 sample of white males. The present value of earnings is calculated using a 5\% interest rate. 
Figure $12 \mathrm{~A}$

Profile of Variance of Uncertainty

High School Sample

NLS/66 vs NLSY/79

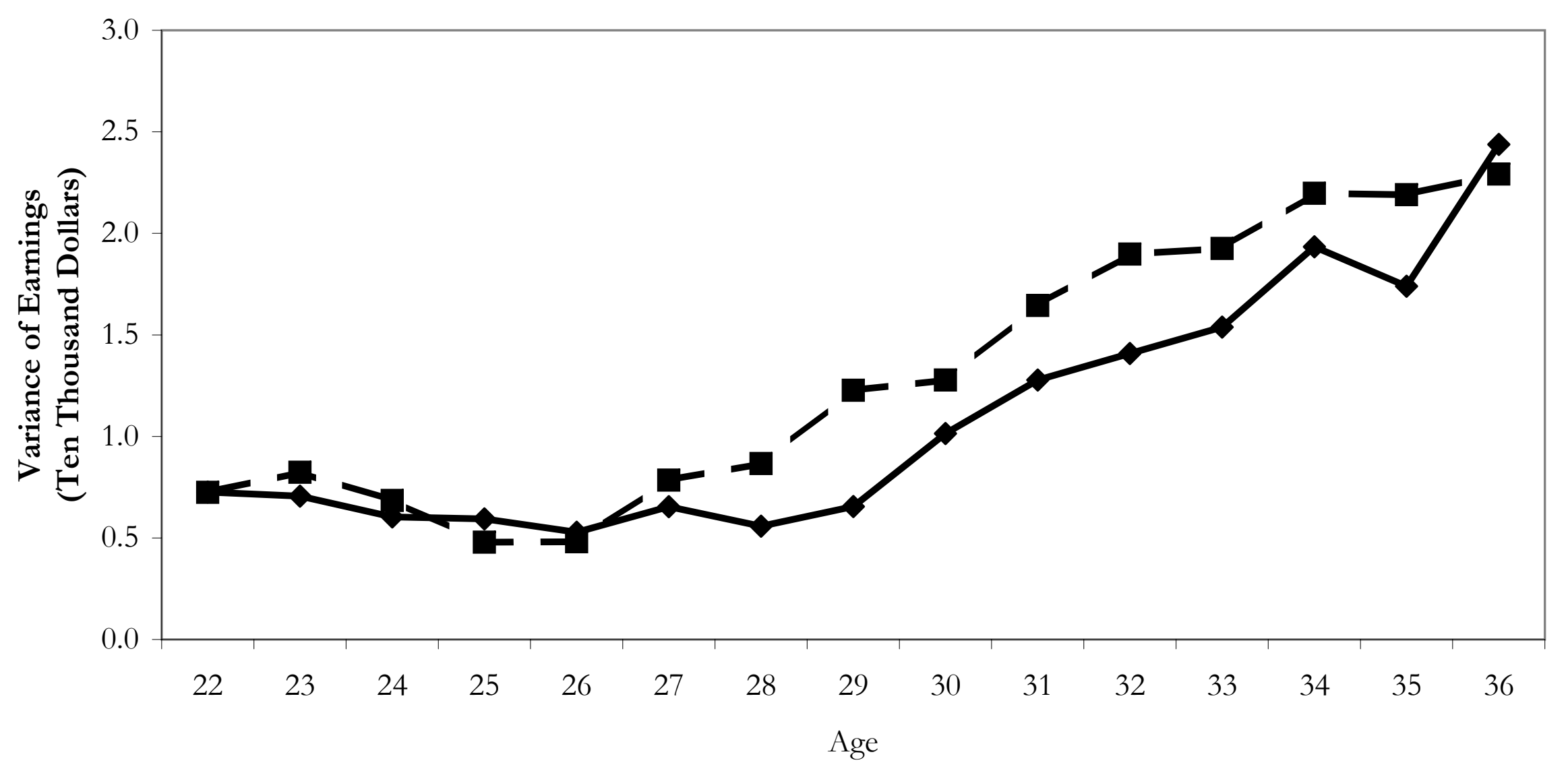

$\rightarrow$ High School - NLS/66 $\rightarrow$-High School - NLSY/79 
Figure 12B

Profile of Variance of Uncertainty

College Sample

NLS/66 vs NLSY/79

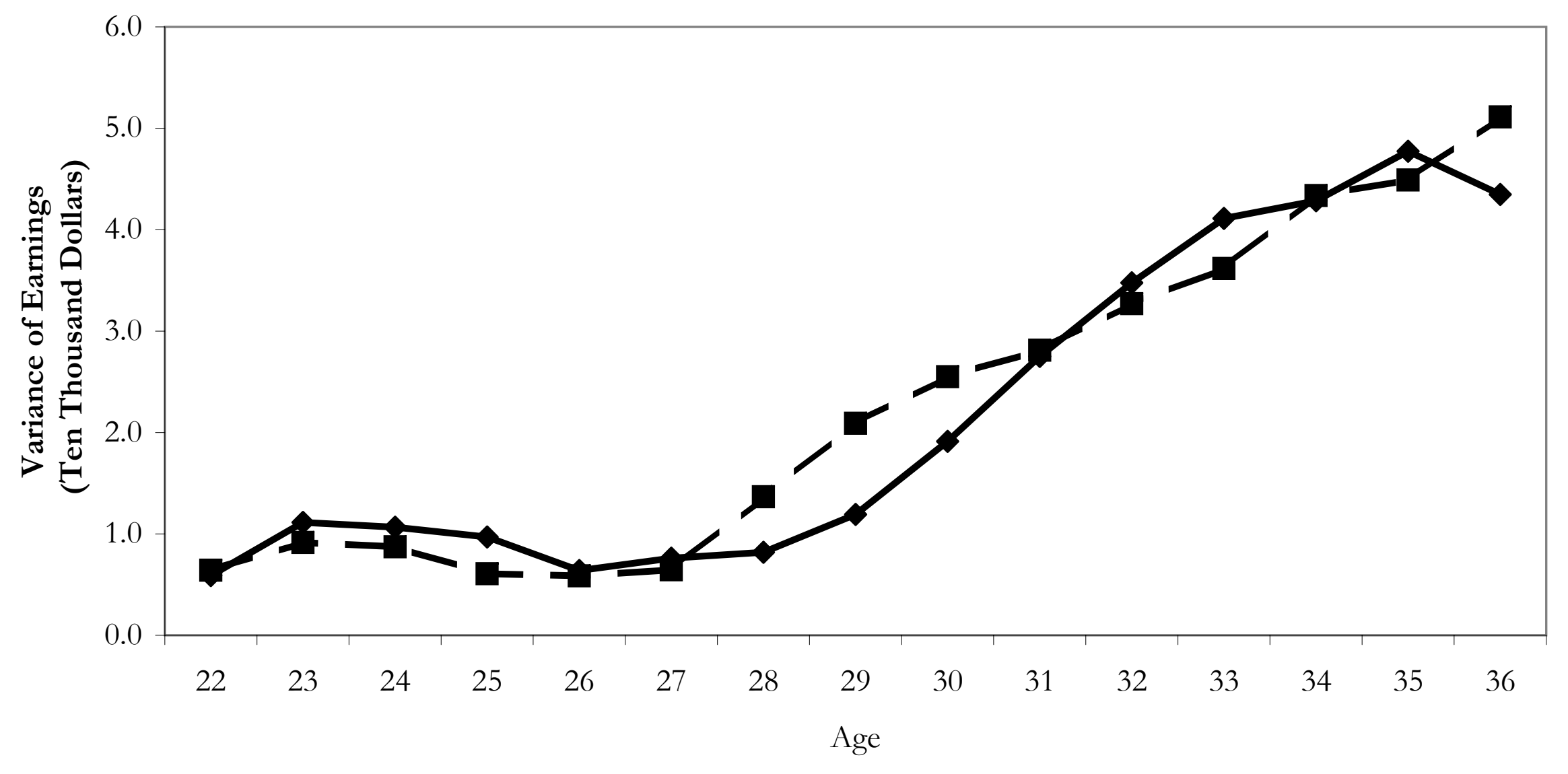

$\rightarrow$ College - NLS/66 -College - NLSY/79 
Figure 13A

Profile of Variance of Heterogeneity Forecastable Components of Variance by Age High School Sample

NLS/66 vs NLSY/79

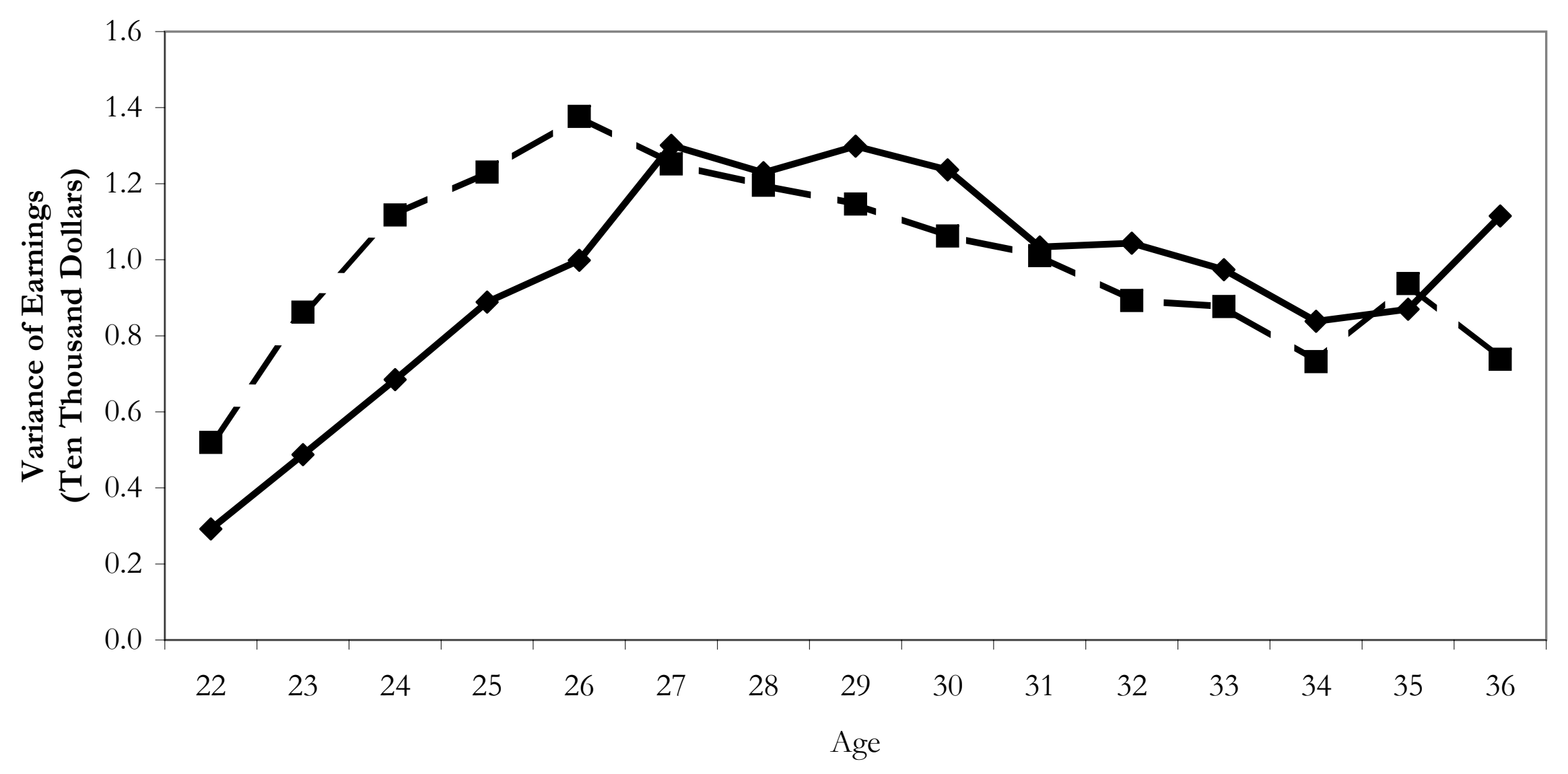

$\rightarrow$ High School - NLS/66 $\rightarrow$-High School - NLSY/79 
Figure 13B

Profile of Variance of Heterogeneity Forecastable Components of Earnings by Age

College Sample

NLS/66 vs NLSY/79

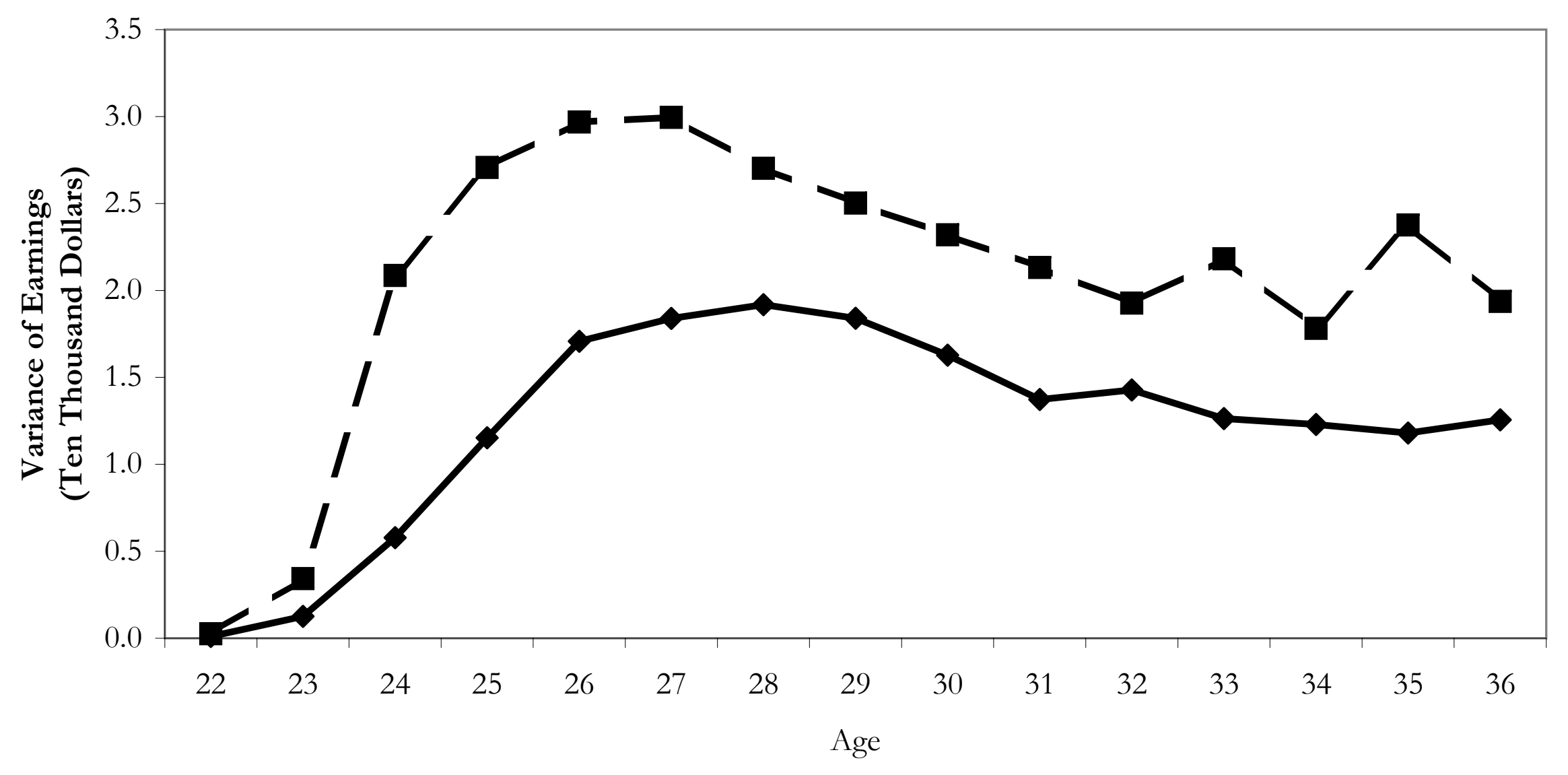

$\rightarrow$ College - NLS/66 -College - NLSY/79 